NBER WORKING PAPER SERIES

\title{
EXCESSIVE ENTRY AND EXIT IN EXPORT MARKETS
}

\author{
Hiroyuki Kasahara \\ Heiwai Tang \\ Working Paper 25878 \\ http://www.nber.org/papers/w25878 \\ NATIONAL BUREAU OF ECONOMIC RESEARCH \\ 1050 Massachusetts Avenue \\ Cambridge, MA 02138 \\ May 2019
}

We thank Pietro Montanarella for excellent research assistance and participants in the NBERTCER-CEPR Conference on "Globalization and Welfare Impacts of International Trade", especially our discussant, Daisuke Fujii, for comments. The views expressed herein are those of the authors and do not necessarily reflect the views of the National Bureau of Economic Research.

NBER working papers are circulated for discussion and comment purposes. They have not been peer-reviewed or been subject to the review by the NBER Board of Directors that accompanies official NBER publications.

(C) 2019 by Hiroyuki Kasahara and Heiwai Tang. All rights reserved. Short sections of text, not to exceed two paragraphs, may be quoted without explicit permission provided that full credit, including (c) notice, is given to the source. 
Excessive Entry and Exit in Export Markets

Hiroyuki Kasahara and Heiwai Tang

NBER Working Paper No. 25878

May 2019

JEL No. D8,F1,F2

\begin{abstract}
$\underline{\text { ABSTRACT }}$
Using transaction-level data for all Chinese firms exporting between 2000 and 2006, we find that on average $78 \%$ of exporters to a country in a given year were new exporters. Among these new exporters, an average of $60 \%$ stopped serving the same country the following year. These rates are higher if the destination country is a market with which Chinese firms are less familiar. We build a simple two-period model with imperfect information, in which beliefs about their foreign demand are determined by learning from neighbors. In the model, a high variance of the prior distribution of foreign demand induces firms to enter new markets. This is because the profit function is convex in perceived foreign demand due to the option of exiting, which insures against the risk of low demand realization. We then use our micro data to empirically examine several model predictions, and find evidence to support the hypothesis that firms' high entry and exit rates are outcomes of their rational self-discovery of demand in an unfamiliar market.
\end{abstract}

Hiroyuki Kasahara

University of British Columbia

Department of Economics

997 - 1873 East Mall

Vancouver, BC V6T 1Z1

Canada

hkasahar@mail.ubc.ca

Heiwai Tang

Johns Hopkins University

1740 Massachusetts Avenue, NW

Washington, DC 20036

hwtang@jhu.edu 


\section{Introduction}

Research shows that firms' turnover (entry and exit) rates are much higher in foreign markets than in domestic markets. ${ }^{1}$ This suggests that firms face considerable uncertainty in new foreign markets. Existing theoretical studies postulate that firms can learn about idiosyncratic demand by experimenting with exports to new markets themselves. In practice, however, firms typically attempt to acquire as much information as possible from other firms before undertaking any risky decisions (Hausmann and Rodrik, 2003), especially when this exploration of foreign markets can entail significant sunk costs. ${ }^{2}$ While economists have studied how learning from neighbors determines individuals' decisions (e.g., Foster and Rosenzweig, 1995, 2010; Conley and Udry, 2010; Moretti, 2011), it has not received the same level of attention in the study of export dynamics.

This paper studies the roles of information and learning from others in shaping firms' export dynamics. We first establish several stylized facts using transaction-level trade data for the universe of Chinese exporting firms over the period of 2000-2006. We find that

1. The majority of firms exporting to foreign countries are new exporters $(78 \%$ on average across 180 countries).

2. Among these new exporters, on average $60 \%$ did not continue to serve the same country the following year.

3. Firms' exit and entry rates are strongly and positively correlated across destination countries.

4. These entry and exit rates are particularly high for exports to new markets, especially to markets with which Chinese exporters are less familiar, like those in Africa (where $83 \%$ of exporters on average are new, and among which $68 \%$ stopped exporting to the same country the following year).

5. Both firms' entry and exit rates are negatively correlated with destination countries' GDP.

\footnotetext{
${ }^{1}$ According to Bartelsman, Haltiwanger, and Scarpetta (2009), the average turnover (entry + exit) rate in the domestic market is $5-10 \%$, and is several order of magnitude bigger in foreign markets, as shown by Eaton et al. (2008), Albornoz et al. (2011), and Blum et al. (2013).

${ }^{2}$ Research in international trade has emphasized how high sunk costs of exporting shape export patterns. Das et al. (2007) and Dickstein and Morales (2018), among others, have provided sizeable estimates of those costs. Notice that high sunk costs could explain low export entry rate, but not the marjority of small firms among export starters.
} 
6. Both firms' entry and exit rates are positively correlated with the distance from destination countries.

These facts are intriguing. One can argue that as fast-growing firms are often seeking new markets, the high entry rates in many foreign markets among Chinese exporters may not be surprising given the rapid growth of both the Chinese economy and its firms during the sample period. That said, it is surprising to see such high firms' exit rates after their first year of exporting. If sunk costs are high, as is commonly assumed in heterogeneousfirm models in trade, embedding the standard Melitz-type model in a dynamic setting with firms' perfect knowledge about future productivity or demand shocks will not be sufficient to explain such high exit rates (see, for instance, Ruhl and Willis, 2017). To do so, we will need a model that features ex-ante uncertainty in firm-specific demand.

One may propose two intuitive reasons to rationalize such high firms' entry and exit rates. The first is that new destinations are characterized with high risks but high returns. A dispersed distribution of firm-specific demand with a thick right tail (e.g., a log-normal distribution of firm export sales) may induce firms to rationally enter a new market when the expected sum of profits exceeds the sunk cost of entry. Ex post, however, only a small fraction of firms survive, with some making large profits. The second potential reason is simply that firms are irrationally optimistic about the market's demand, relative to its true level.

To guide our empirical analysis of the reasons behind firms' excessive entries and exits in foreign markets, we develop a simple two-period model of firms' export decisions when the true individual demand in foreign markets are unknown to the firms. At the beginning of the first period, a firm decides whether to export to a foreign market or not, given the prior distribution of the true demand. If it decides to export, it will learn about the true demand at the end of the first period. In the second period, it will decide whether to continue exporting to or exit from the foreign market.

Our model predicts that not only high expected demand but also a large variance of the prior distribution, can induce firms' to enter new markets. It is obvious that a higher expected demand is associated with larger expected profits and therefore more market entries. The reason why a high variance of perceived market demand will also encourage firm entry is less clear. In the model, given the option of exiting from the market as a result of low realized demand, the profit function in the second period is convex in perceived foreign demand. By Jensen's inequality, a higher degree of uncertainty in foreign demand 
translates to a higher expected value of profit in the second period, which encourages more firms to enter foreign markets in the first period. Thus, our model rationalizes "optimism" based on a standard rational agent model, without any specific assumptions about the distribution of demand factors or firms' irrational behavior.

To sharpen our point that information flows shape firms' excessive entries and exits, we also discuss how firms' observations of neighboring firms' export performance in a market change their priors. Based on information inferred from neighbors' export performance in a market, a firm updates its prior about the part of the market demand that is common across firms. However, the signals about foreign market demand are noisy, as observed neighbors' export performance could be affected by individual firms' unobserved product appeals, more so for differentiated products. The model shows that a firm's export decision and post-entry performance depend not only on the number of neighboring exporters serving a particular market, but also the levels and heterogeneity of their export sales, as well as the firm's own prior knowledge about the market. While more neighbors may offer a more precise signal about a foreign market's demand, the strength of the signal - the average performance of the neighbors in the market - also matters. A larger number of neighbors selling in a foreign market will raise the rate of firms' entry into the same market only if the signal is positive, whereas it will actually deter entry when the signal is negative. Our model suggests that to identify potential information spillover in trade, in addition to the stand-alone measures of the number of neighbors serving a foreign market (defined as a country-sector pair) and their average performance in the market, an interaction between the two should be included as a regressor.

Using export transaction-level data for all Chinese exporting firms, we find evidence supporting the main theoretical predictions. We first show that across countries, firms' entry and exit rates are both positively correlated with the distance from the countries, but negatively correlated with their GDP. ${ }^{3}$ Moreover, the number of exporters in a market, which presumably provides information about its demand, is negatively correlated with both the entry and exit rates in the market. This negative correlation is even stronger for homogeneous goods than differentiated goods. These results are consistent with the model predictions that exploratory entry and exit are more intense in unfamiliar markets, and

\footnotetext{
${ }^{3}$ The entry rate of a country in year $t$ is defined as the fraction of exporters that did not sell there in year $t-1$, but started selling in the country in year $t$. The exit rate of a country in year $t+1$ is defined as the ratio of the number of new exporters in a country in year $t$ that ceased exporting to the same country in year $t+1$. These facts are robust to alternative definitions that partially address the phenomenon of one-off exporting. See Section 3 below.
} 
information from other firms is more useful for predicting post-entry export performance in homogeneous product markets.

We then show, at the city-sector-country level, that the exit rate is higher on average in markets that are farther away, even after sector-year and exporting-city-year fixed effects are controlled for. The exit rates for distant markets are lower for differentiated goods, consistent with the idea that firms' decisions are less responsive to new information from neighbors if market demand is more idiosyncratic.

We then use a restricted sample of all Chinese firms exporting to Sub-Saharan Africa to test the model predictions about firms' entries. The choice of this regression sample is partly due to the computational constraints of using the full sample, and partly due to the fact that the continent, which has received rapidly growing imports from China, offers an interesting case for our study. We find that a firm is more likely to enter a new market (a country-sector pair) in Sub-Saharan Africa if the strength of the signal-measured by the average demand factor of the market revealed by existing exporters in the same city exporting to same market - is stronger, more so if the number of such neighbors is higher. These correlations are found even with the inclusion of firm-year fixed effects to control for firms' supply shocks, city-sector-year fixed effects to control for city-level supply shocks, country-sector-year fixed effects to control for countries' demand shocks, and city-country fixed effects to control for historical linkages between a city and a country. ${ }^{4}$

Finally, we find evidence for the option value of waiting. Specifically, we find that the number of future entrants (in years $t+1$ and $t+2$ ) in a market - our proxy for firms' (expected) option value - is negatively correlated with firms' entry rates in a market after controlling for the contemporaneous number of entrants in the same market and an exhaustive set of fixed effects.

The paper is organized as follows. Section 2 briefly reviews the literature. Section 3 describes the data. Section 4 establishes some stylized facts. Section 5 introduces a simple model to guide the empirical analysis. Section 6 presents the results of our empirical analysis. The final section concludes.

\footnotetext{
${ }^{4}$ In particular, city-country fixed effects capture all path-dependent factors that may simultaneously determine new exporters' sales dynamics and neighbors' export performance, avoiding the common "reflection" problem often encountered in the literature on information or technology spillover.
} 


\section{Related Literature}

This paper relates to various strands of literature. First, our paper applies the influential theoretical work on social learning (e.g., Jovanovic, 1982; Banerjee, 1992; Bikhchandani, Hirshleifer and Ivo, 1992) to the study of international trade. It also contributes to the empirical studies that use micro data to test those theories (Foster and Rosenzweig, 1995; Conley and Udry, 2010; Moretti, 2011). ${ }^{5}$

Second, it adds to a recent literature on firms' export dynamics (Eaton, et al., 2008; Albornoz et al., 2012, among others) by showing the low survival rates of exporters in a new market. ${ }^{6}$ The related theoretical literature incorporates self-learning in trade models to rationalize these findings (Rauch and Watson, 2003; Freund and Pierola, 2010; Iacovone and Javorcik, 2010; Albornoz et al., 2012; Nguyen, 2012; Eaton et al., 2014; Timoshenko, 2015; Berman, Rebeyrol, and Vicardm, forthcoming, among others) ${ }^{7}$ whereas we focus on learning from other firms' experience, which is a significant departure from existing studies. ${ }^{8}$ As such, our paper offers a theoretical model as a guide to interpret the findings in the literature about information spillover in trade (e.g., Chen and Swenson, 2008; Greenaway and Kneller, 2008; Koenig et al., 2010, Kamal and Sundaram, 2016).

Third, our paper relates to the early empirical studies on the determinants of exporters' entry and survival (Aitken et al., 1997; Clerides et al., 1998; Bernard and Jensen, 2004). Our work is different from recent research that also uses transactions-level trade data (Alvarez et al., 2008; Cadot et al., 2011) ${ }^{9}$ by focusing on the effects of information flows

\footnotetext{
${ }^{5}$ See Foster and Rosenzweig (2010) for an extensive review of other micro evidence of technology adoption.

${ }^{6}$ For instance, Eaton et al. (2008) show that over half of new exporters in Colombia do not survive into the next year, but survivors account for a significant share of the country's aggregate exports. Albornoz et al. (2012) find that in Argentina only about half of new exporters continue into the second year of exporting. Freund and Pierola (2010) find high entry and exit rates in export markets among Peruvian agricultural exporters. Blum et al. (2013) find that one-third of Chilean exporters enter into and exit from exporting multiple times in a 19-year panel.

${ }^{7}$ For example, Albornoz et al. (2012) build a model that predicts firms' "sequential exporting" strategy, which arises when a firm realizes its export profitability through exporting and then decides whether to serve other destinations based on its past export performance. Nguyen (2012) develops a model that features uncertain foreign demands that are correlated across markets.

${ }^{8}$ A notable exception is Segura-Cayuela and Vilarrubia (2008), who develop a dynamic general equilibrium model, which features uncertainty and learning about country-specific fixed costs. By observing existing exporters' profits in foreign markets, firms update prior beliefs about fixed costs. We focus instdead on learning about foreign demand.

${ }^{9}$ Alvarez et al. (2008) find firm-level evidence from Chile that the probability of exporting in a new market (product or destination) increases with the prevalence of other exporters in the same market. Cadot et al. (2011) find evidence for four Sub-Saharan African countries that the probability of export survival
} 
firms' entries and exits in foreign markets. In addition, by exploring information spillover across destination countries within firms, we can include an exhaustive set of fixed effects to control for unobserved shocks that drive a firm's export decisions. It is worth noting that similar to this paper, Fernandes and Tang (2014) also use the same data set to explore the presence of information spillovers in firms' exporting. The main difference between the two papers is that we take the option value of waiting more seriously in both the theoretical and empirical analyses, and also highlight firms' excessive entries and exits in unfamiliar markets.

Finally, given the reliance on the spatial distribution of existing firms serving different markets, our paper is naturally related to the new economic geography literature (Krugman, 1991; Krugman and Venables, 1995; and Duranton and Puga, 2004). ${ }^{10}$

\section{Data}

The raw data we use in this paper covers monthly export transactions of the universe of Chinese firms between 2000 and 2006. For each transaction, the data set reports the value (in US dollars) and quantity at the product level (over 7000 HS 8-digit categories) to/from each country (over 200 destination and source countries). ${ }^{11}$ The data set also offers information on a firm's ownership type (domestic private, foreign, and state-owned) and trade regime (processing versus non-processing) in which it registered, as well as the prefecture city it is located. We study learning from neighboring exporters in the same city. There are on average 425 cities plus municipalities, according to China's Customs' definition. ${ }^{12}$

We aggregate all observations to the annual frequency to alleviate measurement issues related to infrequent trade that varies across products or countries. In the empirical analysis, we will focus on learning about demand in a market, which is defined as a country-HS2 pair.

All firms in China engaged in international trade are required by Chinese law to register as either processing exporters or non-processing (ordinary) exporters. ${ }^{13}$ The majority of

increases with the presence of other firms' exporting the same product to the same country. Our model, together with that of Fernandes and Tang (2014), offer theoretical insights to rationalize their findings.

${ }^{10}$ See Ottaviano and Puga (2004) for a survey of the new economic geography literature.

${ }^{11}$ Example of a product: 611241 - Women's or girls' swimwear of synthetic fibres, knitted or crocheted.

${ }^{12}$ The number of cities in our sample increses from 408 in 2000 to 425 in 2006.

${ }^{13}$ Since the beginning of economic reforms in the early $1980 \mathrm{~s}$, the Chinese government has implemented 
processing exporters have long-time committed foreign buyers (e.g. Foxconn has Apple as the single most important long-time customer). One would be concerned that for processing exporters, the room for learning about foreign demand is limited, as the related information is often provided directly by the foreign partner. Without a convincing way to separate out information provided by foreign buyers, we will exclude all processing firms and trading companies (e.g., wholesale-retail firms) from the sample used in the empirical analysis below.

\section{Stylized Facts}

Our empirical analysis relies on the fact that firms enter and exit foreign markets actively. Table 1 presents summary statistics about the number of countries served by (nonprocessing) exporters. The average number of countries served by an exporter ranges between 5 and 6 , with the median fluctuating between 2 and 3 . The large number of multicountry exporters permits us to examine the within-firm variation in export performance across countries, even after we control for firm-year fixed effects in the regressions.

We first document several stylized facts about Chinese firms' exporting dynamics. The first set of facts are about the very high entry and exit rates into different foreign markets among Chinese exporters. As reported in the first row of Table 2, we find that across the $180+$ countries in our sample over 6 years (2001-2006), the entry rates, defined as the fraction of exporters selling in a country in year $t$ that did not sell there in year $t-1$, average around $78 \% .{ }^{14}$ Among these new exporters, a majority of them stopped exporting to the same market the following year. Specifically, the second row shows that the exit rates, defined as the fraction of new exporters that ceased exporting to the same country in the year right after the year of entry, average around $60 \%$ across all countries and years. ${ }^{15}$

various policies to promote exports and foreign direct investment. Most notable of all is the exemption of tariffs on imported materials and value-added tax for processing plants, which assemble inputs into final products for foreign buyers. Readers are referred to Naughton (1996), Feenstra and Hanson (2005) and Fernandes and Tang (2012) for more details about the regulatory regimes governing processing firms in China.

${ }^{14}$ The average entry rate is computed as the mean of the average entry rates cross years, with the average entry rate per year computed first as a mean entry rate across destination countries in that year. The entry rate for 2000, the first year in our sample, is excluded in the calculation as it is always equal to 1 by definition.

${ }^{15}$ Using Danish firm-level monthly data, Geishecker et al. (2019) find that 33 percent of firm-productdestination export spells last less than one month. They argue that such "one-off exporting" events are due to unsolicited buyer-side driven exporting. 
One may be worried that the high rates are driven by a few outlying markets that are recently served only by a few firms, which might enter and drop out immediately after some experimentation. In the third and fourth rows, we show comparably high entry and exit rates even for the median country in each sample to invalidate this concern.

We report in Panel B the same set of statistics by focusing on the sample of firms that export to Sub-Sahara Africa, in which Chinese firms' economic engagement has increased substantially. The entry and exit rates are even higher for this restricted sample of firms. In particular, the entry rates and exit rates of a Sub-Sahara Africa country average around $83 \%$ and $68 \%$ across years, respectively. These findings are consistent with the prior that many Chinese firms are less familiar with the African markets than other markets.

One may also be concerned that our results simply reflect the phenomenon of occasional exporting (e.g., Blum, Claro and Horstmann, 2013 and Geishecker et al., 2019). It is possible that our identified new exporters might have already sold in a market in year $t-2$ or even before, but somehow stopped exporting to the market for one year in $t-1$. Similarly, our identified exiters might somehow stop exporting to a market for one year in $t+1$, but then came back in year $t+2$ or any future years. To examine the potential issues related to this occasional exporting, we report in Table 3 the entrants in a market in 2001, that exited in 2002, and re-entered in subsequent years. Across all country-HS2 markets, there were 133,972 new export transactions by firms that did not serve those markets in 2000. Of those 133,972 transactions, $64 \%$ exited from the markets in 2002 , but $5 \%, 2.4 \%$, $1.3 \%$, and $0.9 \%$ re-entered the same markets in 2003, 2004, 2005, and 2006, respectively. While the percentage of exits that lasted for only one year were not trivial, the cumulative rate of re-entry between 2003 and 2006, among those that exited for one year in 2002 is only $15 \%$. It is unlikely that the patterns shown in Table 2 and in the rest of the paper are largely driven by occasional export entries and exits.

To alleviate the concerns for occasional exporting, in all empirical analyses in the rest of the paper, we use a more restrictive way than the standard approach to define entries and exits. In particular, an entry is defined as a firm's export transaction in a market (a country or a country-sector) in year $t$ but not in years $t-1$ and $t-2$. Symmetrically, an exit is defined as a firm's export transaction in a market that is observed in year $t$ but not in years $t+1$ and $t+2$. Because of the data requirement to observe a firm's export status 2 years before an entry, the sample we use to analyze entries is a reduced panel with 2002 as the first sample year. Likewise, since we need two years of observations after an entry to define exits, the sample we use to analyze exits is an even a shorter panel that 
covers only three years from 2002 to 2004. It is worth noting that all our empirical results below remain robust to using a longer panel of firms with firms' entries and exits defined in the standard way, which only require information on a firm's export status either the year before or after the year of the firm's first year of exporting to a market.

Using the cohort of entrants in 2003 with the restrictive definitions of entries and exits, we show in Figure 1 a tightly positive relationship between firms' entry and exit rates across countries (for 2003). Figure 2 shows the same positive relationship across countries for differentiated and homogeneous products, using the classifications proposed by Rauch (1999). ${ }^{16}$ The positive correlation appears to be higher for differentiated products, suggesting that for the same entry rate per market, a larger fraction of firms exit. To the extent that differentiated goods are intuitively associated with more firm-specific idiosyncratic demand factors, the degree of ex ante uncertainty should be higher, which will be associated with higher ex-post exit rates.

These facts are, to the best of our knowledge, novel relative to those documented in the literature. High entry rates may not be surprising as the Chinese economy and its firms are growing during the sample period. However, it is surprising to see such high exit rates in those markets. If sunk costs are high, the standard dynamic heterogeneous-firm model in trade, say the dynamic extension of Melitz (2003) that features stochastically growing firm productivity and perfect information, cannot rationalize such high exit rates. To guide our empirical exploration of the reasons behind these intriguing stylized facts, we introduce a simple two-period model with imperfect information next.

\section{A Simple Model}

The facts documented above motivate us to develop a model in which firms face ex-ante uncertainty in demand, and form expectations about market-specific demand when making export decisions. We develop a two-period model in which firms do not know the exact level but only the distribution of a foreign country's market demand. At the beginning of the first period, a firm decides whether it exports to a foreign market or not given the prior distribution over the true demand; if it decides to export, then it will learn about the true demand at the end of the first period. It can always wait for a period and decides

\footnotetext{
${ }^{16}$ Specifically, the product differentiation indicator is set to 1 for a sector (HS2) if at least half of the HS 4-digit products within that HS2 are classified by Rauch (1999) as differentiated goods. A concordance is used to map each SITC 4-digit (Rev 2) to multiple HS 4-digit categories.
} 
to export in the second period when the signal about the foreign market's demand may become more precise. In the second period, for those that decided to export in the first period, a firm will decide if it will continue to export or exit from the foreign market.

\subsection{Setup and notations}

To focus on the main mechanisms at work, we make a number of simplifying assumptions. Consider a set of firms with heterogenous productivity. Each firm is endowed with firmspecific productivity $\varphi$, which is known to the firm and remains constant over time. The density function of $\varphi$ for the firms that are not exporting at the beginning of first period is given by $g(\varphi)$.

The true demand in a foreign market, denoted by $x^{*}$, is fixed and non-stochastic. A firm does not know the value of $x^{*}$ at the beginning of the first period, and holds a prior belief that $x$ is distributed normally with mean $\mu$ and variance $\sigma^{2}$ :

$$
x \sim N\left(\mu, \sigma^{2}\right)
$$

Given the productivity $\varphi$ and the demand level $x$, the per-period profit of exporting to foreign market is given by

$$
\pi(x, \varphi)=x+\varphi-f
$$

where $x+\varphi$ is interpreted as the gross profit while $f$ is interpreted as the per-period fixed cost of exporting. ${ }^{17}$

Denote the firm's export decision in the period $t$ by $d_{t} \in\{0,1\}$ for $t=1,2$, where $d_{t}=1$ indicates that a firm exports in period $t$.

\subsection{The second period after exporting in the first period}

At the end of the first period, the true value of foreign demand $x^{*}$ is revealed to the firms who exported in the foreign market. A firm will export in the second period if $\pi\left(x^{*}, \varphi\right) \geq 0$, i.e.,

$$
d_{2}=1 \quad \text { if } \quad x^{*}+\varphi \geq f .
$$

\footnotetext{
${ }^{17}$ Unlike in Fernandes and Tang (2014), we specify the per-period profit function, $\pi(x, \varphi)$, to be linear in the demand level $x$ so that the per-period profit function is not strictly convex in $x$. In our model, an option to exit is the reason why the profit function in the second period is convex.
} 
In this case, a firm with $\varphi<\varphi_{2}^{*}:=f-x^{*}$ will exit from the foreign market in the second period. Note that the value of $\varphi_{2}^{*}$ does not depend on the prior belief.

\subsection{The first period}

In the first period, given the prior belief $x \sim N\left(\mu, \sigma^{2}\right)$, a firm's subjective expected profit from the second period is given by

$$
V(\varphi):=E_{x}[\max \{\pi(x, \varphi), 0\}]=\int \max \{x+\varphi-f, 0\}(1 / \sigma) \phi((x-\mu) / \sigma) d x,
$$

where $\phi(t)=(1 / \sqrt{2 \pi}) \exp \left(-t^{2} / 2\right)$.

A firm will receive zero profit in both periods if it decides not to export. On the other hand, the discounted sum of subjective expected profits from the two periods when a firm decides to export is $E_{x}[\pi(x, \varphi)]+\beta V(\varphi)$, where $\beta \in(0,1)$ is a discount factor. Therefore, a firm will export in the first period if $E_{x}[\pi(x, \varphi)]+\beta V(\varphi) \geq 0$, i.e.,

$$
d_{1}=1 \quad \text { if } \quad \mu+\varphi-f+\beta \int \max \{x+\varphi-f, 0\}(1 / \sigma) \phi((x-\mu) / \sigma) d x \geq 0 .
$$

In this case, a firm with $\varphi \geq \varphi_{1}^{*}$ will export in the first period, where $\varphi_{1}^{*}$ is uniquely defined by $\mu+\varphi_{1}^{*}-f+\beta \int \max \left\{x+\varphi_{1}^{*}-f, 0\right\}(1 / \sigma) \phi((x-\mu) / \sigma) d x=0$.

The following proposition states that, as the value of $\mu$ or $\sigma$ increases, a firm with lower productivity will be induced to export in the first period and that some firms decide to export in the first period even when the expected per-period profit in the first period is negative.

Proposition 1. (a) $\varphi_{1}^{*}$ is strictly decreasing in $\mu$ and $\sigma^{2}$ and is independent of $x^{*}$. (b) $\mu+\varphi_{1}^{*}-f<0$.

Part (a) of Proposition 1 implies that when a firm is more optimistic (higher value of $\mu$ ) or is more uncertain about foreign demand (higher value of $\sigma^{2}$ ), it has a stronger incentive to export. The fact that a firm is more likely to export when it is more optimistic about foreign demand is intuitive. The effect of $\sigma^{2}$ on an incentive to export is related to the option of exiting from the foreign market in the second period when demand turns out to be low. Because a firm has an option to exit, the profit function in the second period, $\max \{x+\varphi-f, 0\}$, is a convex function of $x$. As illustrated in Figure 9, by Jensen's 
inequality, a higher degree of uncertainty in $x$ translates into the higher expected value of $\max \{x+\varphi-f, 0\}$, leading to a stronger incentive to export in the first period.

Part (b) of Proposition 1 implies that firms with $\varphi \in\left(\varphi_{1}^{*}, \bar{\varphi}\right)$ decide to start exporting in the first period although their expected first-period profit is negative, where $\bar{\varphi}$ is defined by the zero-profit condition $\mu+\bar{\varphi}-f$.

In sum, our model shows that the high exit rates in the second period arise when the mean and the variance of the prior distribution over the true demand in the initial period are high. In the model, the high mean value of the prior distribution induces entries due to "optimism" and will lead to exits after learning the true demand. A high variance of $x$ also results in more entries in the first period because a firm has an incentive to learn about the true demand in a foreign market by hoping that the true demand is really high while insuring against the risk of low true demand by keeping the option to exit from the foreign market.

\subsection{Exit rates in the second period}

Consider a set of firms who have different productivity $\varphi \sim_{i i d} g(\varphi)$ but share a common prior belief over the true demand. We now analyze how the average exit rates in the second period among firms who start exporting in the first period depends on their prior belief characterized by the value of $\mu$ and $\sigma^{2}$.

We impose the following assumption to exclude a trivial case that all firms continue to export in the second period.

Assumption 1. $\varphi_{2}^{*}>\varphi_{1}^{*}$.

Figure 10 illustrates a firm's entry and exit decision as well as the determination of exit rate. The density function of $\varphi$ among firms who decided to export in the first period is given by $g(\varphi) /\left(1-G\left(\varphi_{1}^{*}\right)\right)$ if $\varphi \geq \varphi_{1}^{*}$ and 0 if $\varphi<\varphi_{1}^{*}$, where $G(\varphi)$ is the cumulative distribution function of $\varphi$. Because any firm whose productivity is below $\varphi_{2}^{*}$ will exit in the second period, the fraction of firms exiting in the second period (the exit rate) among the firms that start exporting in the first period is given by

$$
\text { exit rate }=\frac{G\left(\varphi_{2}^{*}\right)-G\left(\varphi_{1}^{*}\right)}{1-G\left(\varphi_{1}^{*}\right)}
$$

Because $\varphi_{2}^{*}$ is independent of $\mu$ and $\sigma^{2}$, together with $G\left(\varphi_{2}^{*}\right)<1$, the following is a direct consequence of Proposition 1 and (1). 
Proposition 2. Suppose that Assumption 1 holds and $x^{*}$ is finite. Then, the exit rate in the second period among the firms that start exporting in the first period, as defined in (1), is increasing in the value of $\mu$ and $\sigma^{2}$.

In an extreme case, as $x^{*} \rightarrow-\infty$ so that exporting becomes not profitable to any firms, the exit rate in the second period approaches 1 while some firms will choose to export in the first period as long as their prior mean $\mu$ is finite.

\subsection{Learning from neighbors}

Let us now extend the model to incorporate learning from neighboring firms, in an attempt to show how firms respond to available information. Realistic learning implies that firms will never be able to learn the true demand within finite time. As such, we need to introduce some frictions in learning in the form of firm-specific demand factor. Specifically, let us suppose that the per-period profit of exporting to foreign market is now given by

$$
\pi(x, \varphi)=x+\varphi+z-f
$$

where $z \sim N\left(0, \sigma_{z}^{2}\right)$ is a firm-specific demand attribute, which is unknown to the firm when it makes an export decision.

Different from most existing papers on learning to export that focuses on learning from one's own experience, we focus on learning from neighboring firms instead (see also Fernandes and Tang, 2014). A firm updates its subjective distribution of $x$ by observing neighboring firms' (indexed by $j$ ) export sales in the same market. Suppose that the firm knows each neighbor's productivity. It can then extract a signal for $x$ from its revenue from selling in the same market as

$$
\zeta_{j}:=x+z_{j}=\ln R_{j}-\varphi_{j}
$$

In Section 6 below, we will discuss how to compute $\varphi_{j}$ and thus $\zeta_{j}$ based on this formula, using only trade data.

Given the subjective mean and variance $\left(\mu_{0}, \sigma_{0}^{2}\right)$ in the initial period, the updated subjective mean and variance $\left(\mu, \sigma^{2}\right)$ at the beginning of next period, after observing neighboring firms' exports, are determined by the number of new exporters $n$ in neighborhood in the current period and the signal $\bar{\zeta}:=\frac{1}{n} \sum_{j=1}^{n} \zeta_{j}$. Specifically, in the way proposed by 
DeGroot (2004), the posterior mean and variance are

$$
\begin{aligned}
\mu & =\delta \bar{\zeta}+(1-\delta) \mu_{0} \quad \text { with } \quad \delta=\frac{n \sigma_{0}^{2}}{\sigma_{z}^{2}+n \sigma_{0}^{2}} \\
\sigma^{2} & =\frac{\sigma_{z}^{2} \sigma_{0}^{2}}{\sigma_{z}^{2}+n \sigma_{0}^{2}}
\end{aligned}
$$

Comparative static exercises show that

$$
\begin{aligned}
& \frac{\partial \mu}{\partial \bar{\zeta}}=\delta>0, \quad \frac{\partial^{2} \mu}{\partial n \partial \bar{\zeta}}=\frac{n \sigma_{0}^{2}}{\left(n \sigma_{0}^{2}+\sigma_{z}^{2}\right)^{2}}>0, \quad \frac{\partial^{2} \mu}{\partial \sigma_{z}^{2} \partial \bar{\zeta}}=-\frac{n \sigma_{0}^{2}}{\left(n \sigma_{0}^{2}+\sigma_{z}^{2}\right)^{2}}<0 \\
& \frac{\partial \sigma^{2}}{\partial n}=-\frac{n \sigma_{0}^{4}}{\left(n \sigma_{0}^{2}+\sigma_{z}^{2}\right)^{2}}<0, \quad \frac{\partial \sigma^{2}}{\partial \sigma_{0}^{2}}=\frac{n \sigma^{2}}{\left(n \sigma_{0}^{2}+\sigma_{z}^{2}\right)^{2}}>0 \\
& \lim _{\sigma_{z}^{2} \rightarrow \infty} \frac{\partial \sigma^{2}}{\partial n}=0, \quad \lim _{\sigma_{z}^{2} \rightarrow \infty} \frac{\partial \sigma^{2}}{\partial \sigma_{0}^{2}}=0 .
\end{aligned}
$$

Because a higher $\mu$ will induce a firm to start exporting, the comparative static result in (3) implies the following proposition.

Proposition 3. The likelihood of a firm's starting to export to a foreign market is increasing in the strength of the signal about the market's demand (high $\bar{\zeta}$ ) inferred from neighbors' exports, and more so if the signal is revealed by more exporting neighbors (high $n$ ) and less so if the product is differentiated (high $\sigma_{z}^{2}$ ).

In view of Proposition 1, equation (4) implies that, conditioning on the strength of the signal, an incentive to export is smaller when the number of exporting neighbors $(n)$ is larger or when the initial uncertainty $\left(\sigma_{0}^{2}\right)$ is smaller. Furthermore, equation (5) implies that the effect of the number of exporting neighbors or the initial uncertainty on export decision approaches zero as the value of $\sigma_{z}^{2}$ increases.

Proposition 4. Conditional on the strength of the signal, the likelihood of a firm's starting to export to a foreign market is decreasing in the number of exporting neighbors and increasing in the initial uncertainty, but these effects can be arbitrarily small for sufficiently differentiated products.

In view of Proposition 2, the exit rate among new exporters is related to $\mu$ and $\sigma^{2}$ at the time of entry as implied by Propositions 3-4. Therefore, Propositions 2-4 lead to the following predictions. 
Prediction 1 (Exit Rates) The exit rate among firms that start exporting to a foreign market is increasing in the expected level $(\mu)$ and uncertainty $\left(\sigma^{2}\right)$ about the market's demand. The relationship between the exit/entry rate and uncertainty is stronger for homogeneous goods than for differentiated goods, as learning is less effective for the latter.

Prediction 2 (Strength of Signals and Entry Decisions) The entry rate among the firms that have not exported before increases with the strength of the signal (high $\bar{\zeta})$, especially so when the number of exporting neighbors is large and when the product is homogeneous.

\subsection{The model with one-time sunk cost and the option value of waiting}

Now suppose that, in addition to the per-period fixed cost $f$, a firm has to pay one-time sunk cost $K$ to start exporting. In such a case, a firm has an incentive to wait for exporting if it anticipates that the value of $x$ will be revealed through learning from exporting neighbors.

Consider two extreme cases. In the first case, a firm anticipates that no neighbors start exporting $(n=0)$ so that no additional learning happens in the second period. Then, a firm will export in the first period if the expected sum of profits over two periods is greater than 0 , i.e.,

$$
\mu+\varphi-f-K+\beta E_{x}[\max \{x+\varphi-f, 0\}] \geq 0 .
$$

Let $\bar{\varphi}^{0}$ be the value of $\varphi$ such that (6) holds with equality so that a firm will export in the first period iff $\varphi \geq \bar{\varphi}^{0}$.

In the second case, a firm anticipates that it will perfectly learn the value of $x$ with $n \rightarrow \infty$. Then, a firm will export in the first period if the expected sum of profits over two periods when it starts exporting in the first period is greater than the expected sum of profits if a firm does not export in the first period and it decides to export or not in the second period after learning the value of $x$, i.e.,

$$
\mu+\varphi-f-K+\beta E_{x}[\max \{x+\varphi-f, 0\}] \geq \beta E_{x}[\max \{x+\varphi-f-K, 0\}] .
$$

Let $\bar{\varphi}^{\infty}$ be the value of $\varphi$ such that (7) holds with equality so that a firm will export in the first period iff $\varphi \geq \bar{\varphi}^{\infty}$.

Proposition 5. $\bar{\varphi}^{\infty}>\bar{\varphi}^{0}$ 
Therefore, due to the option value of waiting, a firm with $\varphi \in\left(\bar{\varphi}^{0}, \bar{\varphi}^{\infty}\right)$ will not export in the first period when it anticipates perfect learning while it will do so when no learning on the value of $x$ is anticipated.

We examine the following prediction empirically.

Prediction 3 (Option Value of Waiting) (a) The option value of waiting (i.e., postponed entry) is higher when a firm anticipates that more neighbors start exporting next period. (b) The option value of waiting is lower for differentiated products.

Part (a) of Prediction 3 is an implication of Proposition 5. While we do not offer an explicit theoretical analysis on part (b), the logic behind this prediction is in line with the result of Proposition 5: The incentive to enter a new market is higher for differentiated goods than for homogeneous goods because the option value of waiting is higher for homogeneous goods than for differentiated goods. In an extreme case of no learning from neighbors in differentiated goods, a firm producing differentiated goods can only learn about market demand by entering into a new market, leading to higher entry rates. This implies that, other things equal, entry rates are higher for differentiated goods than for homogeneous goods because firms producing differentiated goods have less incentive to wait for entry.

\section{Empirical Evidence}

\subsection{Suggestive Evidence}

Guided by the model predictions, we first establish a few more facts before presenting our regression results. Given that $\sigma^{2}$ is not directly observed in the data, we use three proxies for uncertainty about a market's demand. The first proxy is the (log) distance between the destination country and China, based on the idea that distance impedes information flows and communication. The second proxy is the (log) number of Chinese entrants to a market. If other firms offer information about a market, the measure of uncertainty about the market should be a decreasing function of the total number of entrants into a market. The third proxy is the (log) GDP of a destination country. The basic idea is that information about larger economies should be more abundant.

Figure 3 shows a positive and significant (with a t-stat of 2.16) cross-country correlation between the entry rate and the destination country's distance from China for the year 
2003. Figure 4 shows instead a positive and significant (with a t-stat of 2.73) cross-country correlation between the exit rate and a destination country's distance from China. The results in both figures are consistent with our model prediction that uncertainty about a country's demand will encourage seemingly excessive firms' entries and thus exits.

Next we explore the relationship between firms' rates of entry into a country and the number of existing Chinese exporters selling there the year before. To address the concern that the relationship is simply capturing the market size effect, we partial out (log) GDP of the destination country by first regressing the (log) number of Chinese exporters in a country on $(\log )$ GDP of the same country, and then taking the residuals as our dependent variable of interest. ${ }^{18}$ Our model predicts that both the entry and exit rates will be negatively correlated with the $(\log )$ number of existing exporters, and the slope is expected to be steeper for homogeneous than differentiated goods. Indeed, Figure 5 shows a statistically significant and negative relationship between the country-specific entry rate and the number of existing exporters in a market (after partialling out the correlation with destination countries' GDP). The relationship is stronger for homogeneous goods than differentiated goods. Through the lens of our model, the idea is that if demand for firms producing differentiated products is more idiosyncratic, information about a market from other firms is less useful.

Figure 6 shows that the rate of firms' exit from a country is negatively correlated with the (log) number of existing exporters (after partialling out the correlation with destination countries' GDP) to the country. Since entry and exit rate are highly correlated and are essentially affected by information asymmetry in the same way, it is not surprising to see such negative correlation, based on the reasons we used to explain the patterns in Figure 5.

Figures 7 and 8 plot the entry and exit rates on the (log) GDP across countries for the year 2003. Both rates are strongly and negatively correlated with the market size of countries. While GDP can be correlated with many other economic fundamentals, the usual conjecture that firms are less likely to enter smaller markets contrasts sharply with the negative correlation we find here. The idea that firms know more about large markets, either because they are more visible or there have been many existing exporters offering information about the market, is consistent with the negative correlation between entry (exit) rates and market size across countries.

\footnotetext{
${ }^{18}$ The pattern is robust to simply using the $(\log )$ number of Chinese firms without partialling out the correlation with countries' GDP.
} 
To sum up, we find that the majority of exporters are new exporters in many countries (78\% on average across 180 countries). Among these new exporters, a majority of them (60\% on average) did not continue to serve the same country the following year. The entry and exit rates are positively and significantly correlated across destination countries. They are particularly high for exports to small and developing countries, especially those in Africa (83\% of exporters on average are new; with $68 \%$ of the entrants stopped exporting to the same country the following year). Both firms' entry and exit rates are negatively correlated with the GDP of destination countries, but positively correlated with the distance from them. These are suggestive evidence so far, and we now come to the firm-level regression analysis, which can tackle various usual suspects behind the suggestive evidence.

\subsection{Empirical Analysis}

This section aims to empirically verify Predictions 1 to 3 .

\subsubsection{Exiting decisions in the first year of exporting}

Prediction 1 states that the exit rate, defined as the fraction of new exporters that exit from a market, should be increasing in the expected level and uncertainty of the market's demand, but less so for differentiated goods than homogeneous goods, as learning from others is more effective for the latter.

To empirically verify Prediction 1 and to confirm more systematically the patterns documented in Figures 4 and 6 about the average exit rate for each market, we estimate the following regression specification:

$$
\operatorname{Exit}_{c, m, s, t}=\alpha+\beta p\left(\sigma_{m, s}^{2}\right)+\delta D i f f_{s} \times p\left(\sigma_{m, s}^{2}\right)+\{F E\}+\epsilon_{c, m, s, t},
$$

where the dependent variable, Exit $t_{c, m, s, t}$, stands for the fraction of firms that enter country $m$ and sector $s$ (a HS 2-digit category) from Chinese city $c$ in year $t$, but stop exporting in the same country-sector market in years $t+1$ and $t+2$.

The regressor of interest, $p\left(\sigma_{m, s}^{2}\right)$, is a proxy for uncertainty about market $m, s$. It is equal to either the (log) distance between China and country $m$ (in that case, the sector subscript $s$ is redundant) or the (log) number of Chinese existing exporters in market $m, s$ in year $t .\{F E\}$ includes sector-year fixed effects to control for all global supply and demand shocks in a sector; and city-year fixed effects to control for any supply shocks 
coming from the region where the firm is located. $\epsilon_{c, m, s, t}$ is the residual.

The variable $\operatorname{Dif} f_{s}$ represents product differentiation of sector $s$. As a proxy, we use the indicator for product differentiation, constructed based on the classification by Rauch (1999), as discussed in Section 4.

A drawback of using Rauch's product differentiation indicators is that it captures not only the importance of firm-specific product appeals that affect demand, but possibly also the inverse of market competition. To the extent that competition can be less intense in differentiated product markets, any positive correlation we find between firms' entries or exits and Rauch's production differentiation indicators may be independent of the information story. To this end, we propose a second measure of $\operatorname{Dif} f_{s}$, based on our model. According to our model, we can use estimated $\sigma_{z}^{2}$, the standard error of firm-specific product appeals $(z)$ in each market (country-sector) and year, as a direct measure of Diff $f_{s}$. To estimate $\sigma_{z}^{2}$, we need to first discuss how to use customs transaction-level data to construct the measure of firms' productivity in each sector.

\section{Estimating firm productivity in each sector and product appeal in each market}

We can estimate firm $i$ 's productivity in sector $s$ and year $t\left(\phi_{i, s, t}\right)$ by estimating the following specification:

$$
\ln R_{i, m, s, t}=\phi_{m, s, t}+\phi_{i, s, t}+\epsilon_{i, m, s, t}
$$

where $\ln R_{i, m, s, t}$ is the $\log$ of firm $i$ 's export sales to country $m$ in sector $s$ in year $t$, while $\phi_{m, s, t}$ is a dummy to absorb the demand factor of the same market in year $t$, which is common to all firms. We estimate this equation using the sample of export sales to countries

outside of Africa, and take the estimated $\phi_{i, s, t}, \widehat{\phi}_{i, s, t}$, as the estimated productivity of firm $i$ in sector $s$. The residual from the estimation $\epsilon_{i, m, s, t}$ will be the empirical counterpart to the firm's product appeal in the market in year $t$.

Using a firm's sector-specific productivity estimate and its market-specific sales, we can then construct a measure of the signal for sector $s$ in country $m$ from every neighboring firm that exports to the same market. The idea is to partial out a firm's $(j)$ sector-specific productivity from its sales in market $m$ and year $t$, as $\zeta_{j, m, s, t}=\ln R_{j, m, s, t}-\hat{\phi}_{j, s, t}$. The average value of the signals among the set of neighboring exporters can be computed as

$$
\bar{\zeta}_{c, m, s, t}=\frac{1}{\left|\mathcal{N}_{c, m, s, t}\right|} \sum_{j \in \mathcal{N}_{c, m, s, t}} \zeta_{j, m, s, t}
$$


where $\mathcal{N}_{c, m, s, t}$ is a set of existing firms that export from city $c$ to market $m, s$ in year $t$. Firms' individual product appeals $\epsilon_{i, m, s, t}$ will be averaged out to 0 empirically, as the underlying distribution is assumed to have mean 0 .

Finally, for each market-year $(m, s, t)$, we can construct a measure of model-based idiosyncrasy of firms' demand $\left(\sigma_{z(m, s, t)}^{2}\right)$ by computing the standard error of the estimated signal $\zeta_{j, m, s, t}$ 's from the set of exporters selling in the same market as:

$$
\hat{\sigma}_{z(m, s, t)}=\sqrt{\sum_{j \in \mathcal{N}_{m, s, t}}\left(\zeta_{j, m, s, t}-\bar{\zeta}_{m, s, t}\right)^{2}} \quad \text { with } \quad \bar{\zeta}_{m, s, t}=\frac{1}{\left|\mathcal{N}_{m, s, t}\right|} \sum_{j \in \mathcal{N}_{c, m, s, t}} \zeta_{j, m, s, t}
$$

where $\mathcal{N}_{m, s, t}$ is the set of exporters to market $m, s$ in year $t$.

Regression Results As described in Section 6.1, we use the restrictive panel that includes all country-sector pairs in which Chinese firms ever started exporting in a new market since 2002, but did not export in the previous two years. Since we need two years after a firm's initial exporting to define exits in a restrictive way, our panel is further reduced to the period between 2002 and 2004.

The results of estimating equation (8) using the restrictive sample are reported in Table 4. Standard errors are clustered by city. In column (1) when we use (log) distance as the proxy for demand uncertainty $\left(\sigma_{m, s}^{2}\right)$, we find that after controlling for sector-year and city-year fixed effects, there is a statistically significant positive correlation between the (log) distance and the rate of firms' exits from the market. In column (2), when we use the $(\log )$ number of firms in the same city (neighbors) that export to market $(m, s)$ to proxy for market uncertainty, we find results that are consistent with those in column (1). Specifically, we find a statistically significant and negative coefficient on (log) number of neighboring firms, suggesting that more neighbors, presumably by providing more information about market $m, s$ to potential entrants, may lower the post-entry exit rates.

We also find that the correlations between the two proxies for market uncertainty and the city-market specific exit rates are weaker for differentiated product markets. Specifically, when we use Rauch's differentiation indicators as proxies for product differentiation in columns (3) and (4), we find a negative and significant coefficient on the interaction term Dif $f_{s} \times p\left(\sigma_{m, s}^{2}\right)$ if $p\left(\sigma_{m, s}^{2}\right)$ is proxied by $(\log )$ distance; and a positive though insignificant coefficient on the interaction term if $p\left(\sigma_{m, s}^{2}\right)$ is proxied by the (log) number of neighbors 
exporting to the market $m, s$ in the same year.

In columns (5) and (6), when Diff $f_{s}$ is measured by our constructed $\hat{\sigma}_{z(m, s, t)}$, the coefficients on the interaction terms $\operatorname{Dif} f_{s} \times p\left(\sigma_{m, s}^{2}\right)$ take the same signs (positive when $p\left(\sigma_{m, s}^{2}\right)$ is log distance and negative when it is (log) number of neighbors) and become statistically more significant. Table A1 in the appendix shows entirely consistent results when we repeat all exercises reported in Table 4 by using provinces, rather than cities, to define neighborhoods. In sum, the results in Table 4 support Prediction 1.

\subsubsection{Learning from neighbors}

Our next exercise is to empirically verify Prediction 2, which is about how learning from neighbors affects firms' entry decisions.

$\operatorname{Entry}_{i, c, m, s, t}=\alpha+\beta \bar{\zeta}_{c, m, s, t}+\theta \bar{\zeta}_{c, m, s, t} \times n_{c, m, s, t}+\delta n_{c, m, s, t}+\gamma \ln \left(T F P_{i, c, s, t}\right)+\{F E\}+\epsilon_{i, c, m, s, t}$.

The dependent variable, Entry $y_{i, c, m, s, t}$, is an indicator for the entry of firm $i$ from city $c$ in market $m$, sector $s$ in year $t$. It is equal to 1 if the firm reports exports to country $m$ in sector $s$ and year $t, 0$ otherwise. Since we are gauging the effects on firms' propensity to enter a market, we drop all existing exporters in a market (i.e., all firms that already exported to market $m, s$ in year $t-1$ ). As explained in the introduction, we use a regression sample that includes all potential markets only in the 46 Sub-Sahara African countries to avoid the computational constraints.

The regressors of interest are the number of neighbors exporting to country $m$, sector $s$ in year $t\left(n_{c, m, s, t}\right)$ and its interaction term with the signal from the neighbors $\bar{\zeta}_{c, m, s, t}$, computed based on (10). Following our comparative statics (3)-(5), we use $n_{c, m, s, t}$ instead of its log version although the results remain qualitatively identical when we use the log of $n_{c, m, s, t}$. Proposition 2 predicts that the propensity to enter a new market, among the firms that have not been exporting in the same market before, increases with the strength of the signal, especially when there are more existing neighboring firms exporting to the same market. Thus, $\beta>0, \theta>0, \gamma>0$, while the sign of $\delta$ is ambiguous.

By exploiting variation in export performance across countries and years within firms, we can include an exhaustive set of fixed effects $(\{F E\})$ to control for many unobserved determinants of new exporters' export dynamics. In particular, in all the regression specifications, we always include city-country fixed effects, which control for the bilateral distance 
between a city and a country, as well as physical distance and any unobserved city-marketspecific determinants of export performance and dynamics, such as historical linkages that may affect the available information and infrastructure for exports from a city to a country. In addition, we control for city-sector-year, country-sector-year, and firm-year fixed effects, respectively. Country-sector-year fixed effects control for any aggregate shocks that may affect the general attractiveness of a market, such as time-varying demand, exchange rates, and economic policies in the importing countries. City-sector-year fixed effects control for any supply shocks, such as government policies, which affect all exporters in a city. Firmyear fixed effects further control for firm productivity shocks. Importantly, by focusing on the within-firm cross-country correlation between new exporters' performance and the prevalence of neighbors' export activities, we address the potential sample selection bias that arises from the endogenous entry decisions that vary across heterogeneous firms.

In addition to the firm-year fixed effects which already capture any firm-specific productivity shocks, we can also control for a firm's sector-specific total factor productivity (TFP), which is estimated based on (9). Including $\ln \left(T F P_{i, c, s, t}\right)$ as a control comes with considerable cost in terms of a significant reduction in sample size, as we can only estimate TFP for firms that export to both Africa and non-African nations within a sector.

Table 5 reports the results of estimating equation (12). Standard errors are clustered at the city-destination level. The results remain robust to clustering by other groups. As shown in column (1), after controlling for country-sector-year fixed effects, city-sectoryear fixed effects, and city-sector-country fixed effects, we find that a firm's probability of entering a market is positively correlated with the strength of the signal, $\bar{\zeta}_{c, m, s, t}$, inferred from the same-market export performance of neighbors in the same city. The learning effect is stronger if there are more neighboring exporters revealing the signal, as suggested by a positive coefficient $(\theta)$ on $\bar{\zeta}_{c, m, s, t} \times n_{c, m, s, t}$. The coefficient $(\delta)$ on the number of neighbors serving the same market $\left(n_{c, m, s, t}\right)$ is actually negative, but our model has no specific prediction about its sign. This set of results remains robust to the inclusion of firm-year fixed effects (column (2)) and firms' sector-level TFP (column (3)). ${ }^{19}$

Next we empirically verify the last part of Prediction 2 about the smaller learning potential for differentiated products. To this end, we include in addition to the baseline regressors, the corresponding interaction terms between the estimated $\hat{\sigma}_{z(m, s, t)}$ and each of the following regressors: $\bar{\zeta}_{c, m, s, t}, \bar{\zeta}_{c, m, s, t} \times n_{c, m, s, t}$, and $n_{c, m, s, t}$. Column (4) shows that

\footnotetext{
${ }^{19}$ When we repeat the same set of regressions but with a neighborhood defined as a province rather than a city, we find consistent and significant results.
} 
while the interaction term $\hat{\sigma}_{z(m, s, t)} \times \bar{\zeta}_{c, m, s, t}$ is insignificant, the coefficient on the triple interaction $\hat{\sigma}_{z(m, s, t)} \times \bar{\zeta}_{c, m, s, t} \times n_{c, m, s, t}$ is negative and significant, suggesting that conditional on a positive signal inferred from a fixed number of neighbors, the learning effect is weaker for the more differentiated products $\left(\right.$ high $\left.\hat{\sigma}_{z(m, s, t)}\right) .{ }^{20}$ The last two columns confirm the robustness of these results by including firm-year fixed effects and firms' sector-level TFP sequentially.

\subsubsection{Option value of waiting}

Our final exercise is to examine Prediction 3, which is about the option value of waiting (i.e., postponed entry). To this end, we estimate the following specification

$$
E_{\text {try }} i_{, c, m, s, t}=\alpha+\beta n_{c, m, s, t+n}^{e}+\delta n_{c, m, s, t}^{e}+\{F E\}+\epsilon_{i, c, m, s, t}
$$

where Entry E,c,m,s,t $_{\text {is }}$ the same dependent variable as in equation (12). For the same computational constraints about the feasible size of the regression sample discussed in the previous section, the regression sample includes only potential markets in Sub-Sahara African countries. As in the previous analysis on firm entry, we drop firms that have already exported to market $m, s$ in year $t-1$.

The first task is to find a way to construct a proxy for the option value. In our model with perfect foresights, we can approximate the option value by the realized number of entrants (not logged) in the future. We therefore use the number of entrants, $n_{c, m, s, t+n}^{e}$, in the following two years as a proxy for the option value of waiting. ${ }^{21}$

As reported in Table 6, we find in column (1) a negative and significant coefficient on the number of future entrants (the total number of entrants in year $t+1$ and $t+2$ ) in a market, after controlling for the number of contemporaneous entrants in the same market $\left(n_{c, m, s, t}^{e}\right)$ and the identical set of fixed effects reported in Table 5. There results are robust to the control of the firm's sector-specific TFP (column (2)).

In columns (3) and (4), we add in addition to the regressors described in (13) the interaction terms between each of the regressors and our estimate of product differentiation, $\hat{\sigma}_{z(m, s, t)}$. We find no significant coefficient on the interaction term between the number of

\footnotetext{
${ }^{20}$ Notice that the stand-alone $\hat{\sigma}_{z(m, s, t)}$ is absorbed by the country-sector-year fixed effects. The number of observations drops when $\hat{\sigma}_{z(m, s, t)}$ is used in interaction terms as there are city-market-years in which there's only one existing exporter (i.e., $\left.\hat{\sigma}_{z(m, s, t)}=0\right)$.

${ }^{21}$ The regression results remain robust to using the number of entrants in the following one year to proxy for the option value of waiting.
} 
future entrants in the same market and $\hat{\sigma}_{z(m, s, t)}$. In sum, even we find significant evidence about the option value of waiting on average, which supports Prediction 3, there is no systematic difference in the option value between homogeneous and differentiated product markets.

\section{Conclusion}

This paper studies the surprisingly high entry and exit rates among Chinese firms selling in foreign markets. We first use a data set that covers all export transactions from Chinese firms to all countries over the 2000-2006 period to document several stylized facts that are new to the trade literature. We find that a majority of exporters to a country are new exporters. More surprisingly, over half of the new exporters in a market stop serving the same market the following year. We also find that a destination country's entry rate, defined as the fraction of exporters that are new, is positively correlated with its exit rate, defined as the fraction of new exporters that stopped exporting in the following years. Both entry and exit rates are negatively correlated with destination countries' market size, but positively correlated with their distance from China.

We build a simple two-period model with imperfect information about foreign demand, in which firms' beliefs about their foreign demand are determined by learning from neighbors. The model predicts that a high variance of the prior distribution of foreign demand induces firms to enter new markets, as the profit function is convex in perceived foreign demand due to the option of exiting. We then use our micro data to empirically examine several model predictions, and find supporting evidence that firms' high entries and exits are outcomes of their rational self-discovery of demand in an unfamiliar market.

In research in progress, we extend the model to a dynamic one and structurally estimate the key parameters in the model. The goal is to quantitatively assess the value of information offered by neighboring firms and the option value of waiting to enter different foreign markets. 


\section{Reference}

1. Aitken, B., G. Hanson and A. Harrison (1997) "Spillovers, foreign investment, and export behavior," Journal of International Economics, 43, 103-132.

2. Albornoz, F., H. Calvo-Pardo, G. Corcos, and E. Ornelas (2012) "Sequential Exporting," Journal of International Economics, 88, 1, 17-31.

3. Alvarez, R., H. Faruq, and R. Lopez (2008) "New Products in Export Markets: Learning From Experience and Learning from Others," Mimeo, Bank of Chile.

4. Banerjee, A. (1992) "A simple model of herd behavior," Quarterly Journal of Economics 107 (3), 797-817.

5. Bartelsman, E., J. Haltiwanger, and S. Scarpetta (2009) "Measuring and Analyzing Cross-country Differences in Firm Dynamics," in Producer Dynamics: New Evidence from Micro Data, ed. T. Dunne, J. Bradford, and M. Roberts.

6. Berman, Nicolas, Vincent Rebeyrol, and Vincent Vicard (2019) "Demand learning and firm dynamics: evidence from exporters." Review of Economics and Statistics 101, no. 1: 91-106.

7. Bernard, A. and B. Jensen (2004) "Why some firms export," The Review of Economics and Statistics, 86(2), 561-569.

8. Bikhchandani, S., Hirshleifer, D. and Welch, I. (1992) "Theory of Fads, Fashion, Custom, and Cultural Change as Informational Cascades?" Journal of Political Economy, 100, 992? 1026 .

9. Blum, B.S., S. Claro, I.J. Horstmann (2013) "Occasional and Perennial Exporters", Journal of International Economics, 90(1), 65-74.

10. Cadot, O., L. Iacovone, D. Pierola and F. Rauch (2013) "Success and Failure of African Exporters," Journal of Development Economics, 101, pp. 284-296.

11. Chen, H. and D. Swenson (2008) "Multinational Firms and New Chinese Export Transactions." Mimeo, University of California, Davis. 
12. Clerides, S., S. Lach, and J. Tybout (1998) "Is Learning by Exporting Important? Micro-dynamic Evidence from Colombia, Mexico, and Morocco," Quarterly Journal of Economics, 113(3), 903-947.

13. Conley, T. and C. Udry (2010) "Learning about a New Technology: Pineapple in Ghana," American Economic Review, 100(1): 35-69.

14. Das, S. and M. Roberts, and J. Tybout (2007), "Market entry costs, producer heterogeneity, and export dynamics," Econometrica, 75 (3), 837-873.

15. DeGroot, M.H. (2004) Optimal statistical decisions. vol. 82. Wiley-Interscience.

16. Dickstein, Michael and Eduardo Morales (2018) "What do Exporters Know?" Quarterly Journal of Economics, Volume 133, Issue 4, 1 November 2018, Pages 1753-1801.

17. Duranton, G. and Puga, D. (2004) "Micro-foundations of urban agglomeration economies," Henderson, J.V., Thisse, J.F. (Eds.), Handbook of Regional and Urban Economics, vol. 4. 2063-2117.

18. Eaton, J., M. Eslava, M. Kugler (2008) "The Margins of Entry into Export Markets: Evidence from Colombia," in Elhanan Helpman, Dalia Marin, and Thierry Verdier, eds., The Organization of Firms in a Global Economy, Cambridge, MA: Harvard University Press, 2008.

19. Eaton, J., M. Eslava, C. J. Krizan, M. Kugler, and J. Tybout (2014) "A Search and Learning Model of Export Dynamics," Penn State University mimeo.

20. Fernandes, A. and H. Tang (2012) "Determinants of Vertical Integration in Export Processing: Theory and Evidence from China," Journal of Development Economics, $99(2), 396-414$.

21. Fernandes, A. and H. Tang (2014) "Learning to export from neighbors" Journal of International Economics, 94 (1), pp. 67-84.

22. Feenstra R. and G. Hanson (2005) "Ownership and Control in Outsourcing to China: Estimating the Property-Rights Theory of the Firm," Quarterly Journal of Economics, 120(2), 729-761. 
23. Foster, A. and M. Rosenzweig (1995) "Learning by Doing and Learning from Others: Human Capital and Technical Change in Agriculture," Journal of Political Economy, 103(6), 1176-1209.

24. Foster, A. and M. Rosenzweig (2010) "Microeconomics of Technology Adoption," Annual Review of Economics, Vol. 2: 395-424.

25. Freund, C. and Pierola M.D. (2010), "Export entrepreneurs: Evidence from Peru," World Bank Working Paper.

26. Geishecker, I., Schröder, P. J. H., and A. Sørensen (2019) "One-off Export Events," Canadian Journal of Economics 52(1), 93-131.

27. Greenaway, David, and Richard Kneller (2008) "Exporting, productivity and agglomeration." European Economic Review 52, no. 5, 919-939.

28. Hausmann, R. and Rodrik, D. (2003) "Economic Development as Self-discovery," Journal of Development Economics, 72(2), pp. 603-633.

29. Iacovone, L and B. Javorcik (2010) "Multi-product exporters: product churning, uncertainty and export discoveries," Economic Journal, 120 (544), 481-499.

30. Kamal, Fariha and Asha Sundaram (2016) "Buyer-Seller Relationships in International Trade: Do Your Neighbors Matter?" Journal of International Economics, September 2016, Vol. 102, 128-140.

31. Koenig, P. F. Mayneris and S. Poncet (2010) "Local Export Spillovers in France," European Economic Review, 54, 622-641.

32. Krugman, P. (1991) "Increasing Returns and Economic Geography," Journal of Political Economy, 99(3), 483-499.

33. Krugman, P. and Venables, A.J. (1995) "Globalization and the Inequality of Nations," Quarterly Journal of Economics, 110, 857-880.

34. Melitz, M. (2003) "The impact of trade on intra-industry reallocations and aggregate industry productivity," Econometrica, 71(6), 1695-1725.

35. Moretti, E. (2011) "Social Learning and Peer Effects in Consumption: Evidence from Movie Sales," Review of Economic Studies, 78(1), 356-393. 
36. Naughton, B. (1996) "China's emergence and prospects as a trading nation," Brookings Papers on Economic Activity 2, 273-343.

37. Nguyen, Dan (2012) "Demand Uncertainty: Exporting Delays and Exporting Failures," Journal of International Economics, 86, 336-344.

38. Ottaviano, G., \& Puga, D. (1998) "Agglomeration in the global economy: A survey of the 'New Economic Geography," World Economy, 21(6), 707-731.

39. Rauch, J. E. (1999) "Networks versus markets in international trade." Journal of International Economics, 48(1), 7-35.

40. Rauch J. and Watson M. (2003) "Starting small in an unfamiliar environment," International Journal of Industrial Organization, 21(7), 1021-1042.

41. Ruhl, KJ, JL Willis (2017) "New exporter dynamics," International Economic Review, 58(3), 703-726.

42. Segura-Cayuela, R., Vilarrubia, J. (2008) "Uncertainty and Entry into Export Markets," Bank of Spain Working Paper.

43. Timoshenko, O. (2013) "Product Switching in a Model of Learning," George Washington University Working Paper. 


\section{Appendix}

\subsection{Proof of Proposition 1}

Using a change of variable $x=\mu+\sigma \epsilon$, we have

$V(\varphi)=\int \max \{\mu+\sigma \epsilon+\varphi-f, 0\} \phi(\epsilon) d \epsilon=(\mu+\varphi-f) \Phi((\mu+\varphi-f) / \sigma)+\sigma \phi((\mu+\varphi-f) / \sigma)$.

Define $W(\mu, \sigma, \varphi)=\mu+\varphi-f+\beta(\mu+\varphi-f) \Phi((\mu+\varphi-f) / \sigma)+\sigma \phi((\mu+\varphi-f) / \sigma)$. Taking a derivative of $W(\mu, \sigma, \varphi)$ with respect to $\varphi, \mu,(1 / \sigma)$, while noting the property of the standard normal density function $\phi^{\prime}(t)=-t \phi(t)$, we have

$$
\begin{aligned}
\frac{\partial W(\mu, \sigma, \varphi)}{\partial \varphi} & =1+\beta \Phi((\mu+\varphi-f) / \sigma)+((\mu+\varphi-f) / \sigma) \phi((\mu+\varphi-f) / \sigma)-((\mu+\varphi-f) / \sigma) \phi((\mu+\varphi-f) / \sigma \\
& =1+\beta \Phi((\mu+\varphi-f) / \sigma)>0 \\
\frac{\partial W(\mu, \sigma, \varphi)}{\partial \mu} & =1+\beta \Phi((\mu+\varphi-f) / \sigma)>0 \\
\frac{\partial W(\mu, \sigma, \varphi)}{\partial(1 / \sigma)} & =(\mu+\varphi-f)^{2} \phi((\mu+\varphi-f) / \sigma)-\sigma^{2} \phi((\mu+\varphi-f) / \sigma)-(\mu+\varphi-f)^{2} \phi((\mu+\varphi-f) / \sigma) \\
& =-\sigma^{2} \phi((\mu+\varphi-f) / \sigma)<0
\end{aligned}
$$

Note that the last equation implies that $\frac{\partial W(\mu, \sigma, \varphi)}{\partial \sigma}>0$.

Define $\varphi_{1}^{*}(\mu, \sigma)$ implicitly by $W\left(\mu, \sigma, \varphi_{1}^{*}(\mu, \sigma)\right)=0$. It follows from the implicit function theorem and $\partial W / \partial \varphi, \partial W / \partial \mu, \partial W / \partial \sigma>0$ that we have $\partial \varphi_{1}^{*} / \partial \mu=-(\partial W / \partial \mu) /(\partial W / \partial \varphi)<$ 0 and $\partial \varphi_{1}^{*} / \partial \sigma=-(\partial W / \partial \sigma) /(\partial W / \partial \varphi)<0$.

\subsection{Proof of Proposition 5}

Note that $\mu+\varphi-f-K+\beta E_{x}[\max \{\mu+\varphi-f, 0\}]$ is strictly increasing function of $\varphi$. Then, the stated result follows from $\beta E_{x}[\max \{\mu+\varphi-f-K, 0\}]>0$. 
Fig 1: Firms' Entry and Exit Rates by Country (2003)

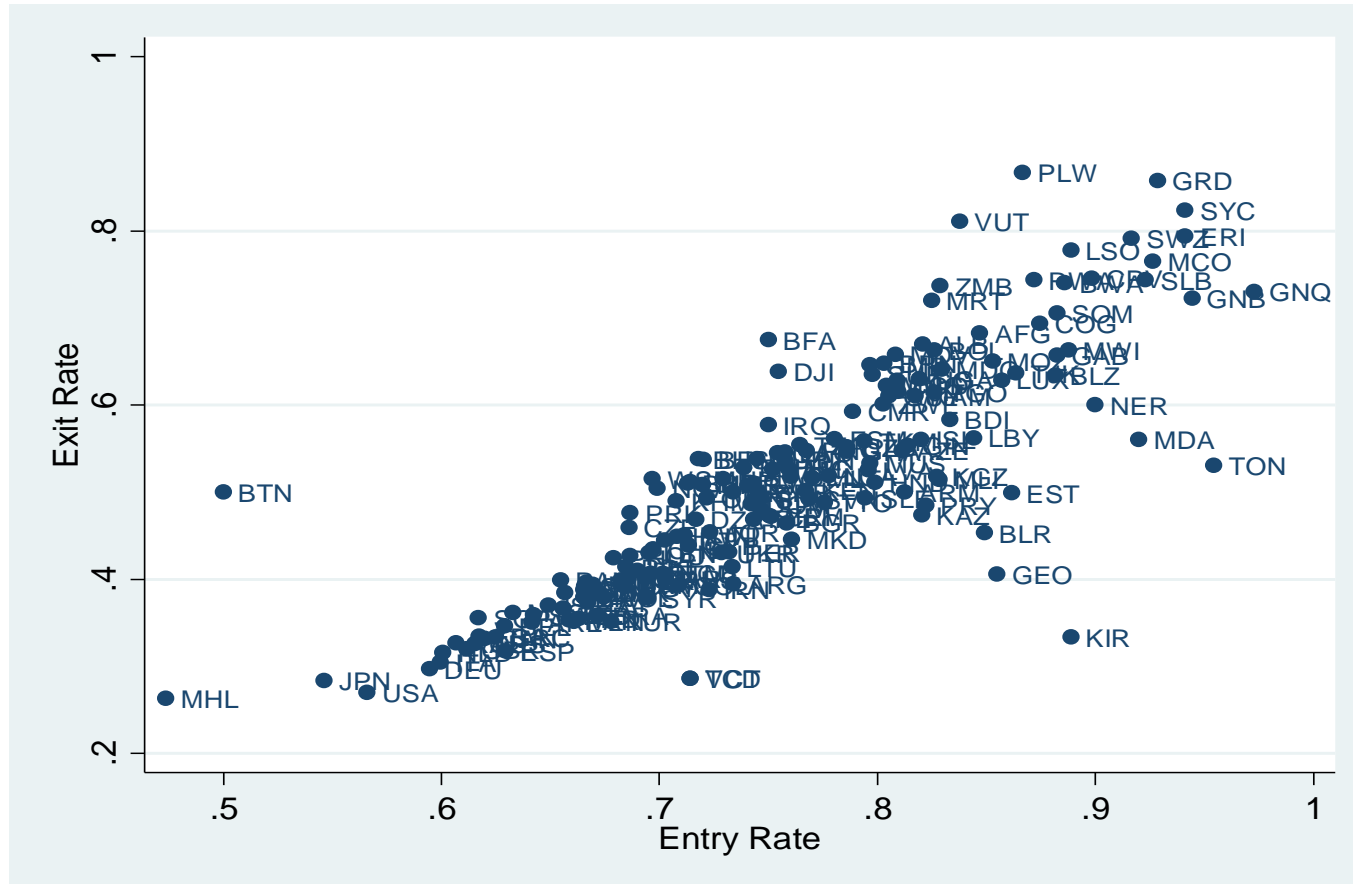

Note: Entry rate $=$ Number of new exporters in $\mathrm{t} /$ Total number of exporters in $\mathrm{t}$. Exit rate $=$ Number of new exporters that exit in $t+1 /$ Number of new exporters in $t$. Re-entrants after exits are not considered as true exits.

Fig 2: Firms' Entry and Exit Rates by Country (2003)

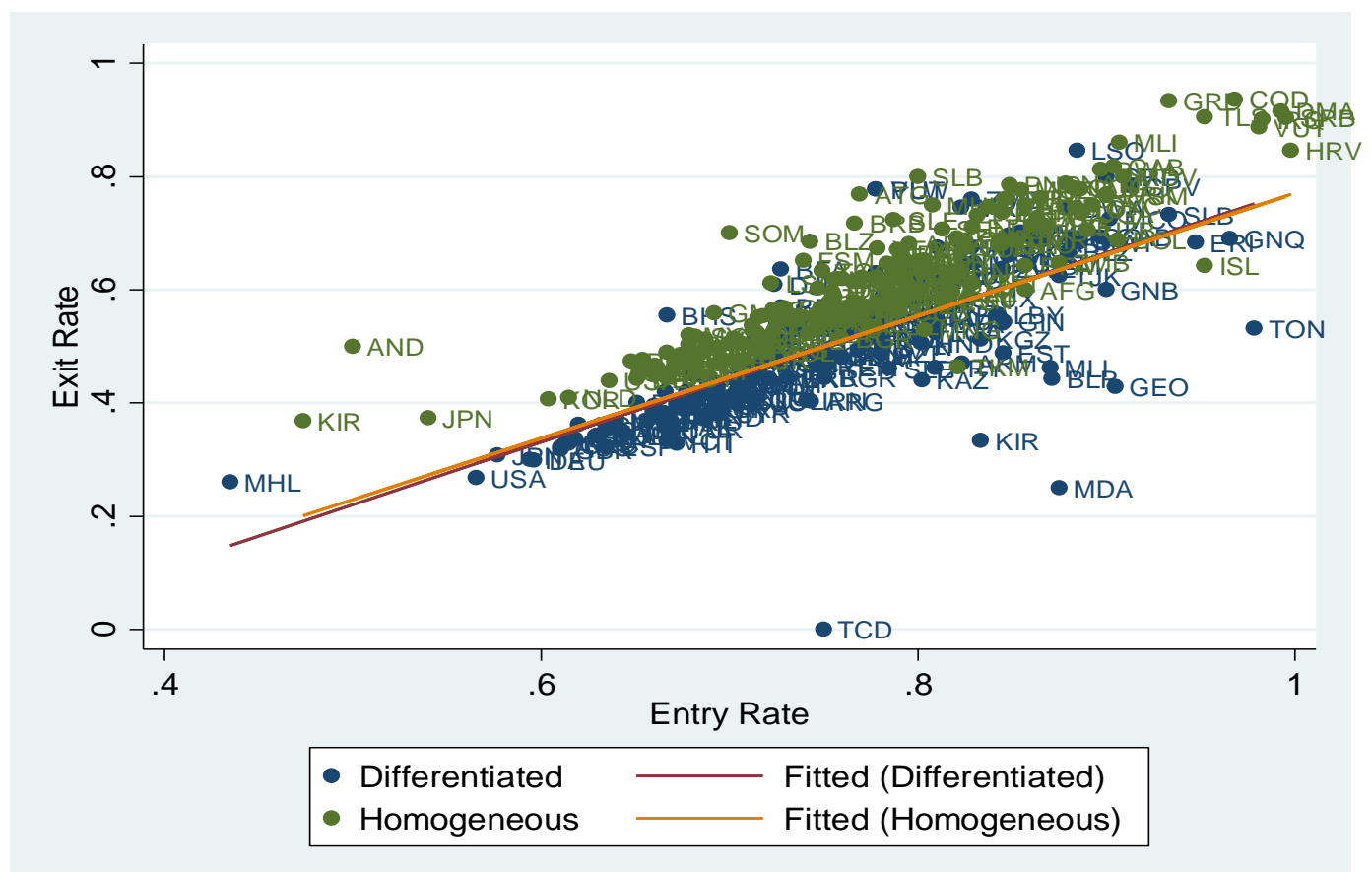

Note: Entry rate $=$ Number of new exporters $(t) /$ Total number of exporters $(t)$; Exit rate $=$ Number of new exporters that exit in $t+1 /$ Number of new exporters in $t$. Re-entrants after exits are not considered as true exits. 
Fig 3: Firms' Entry and Distance by Country (2003)

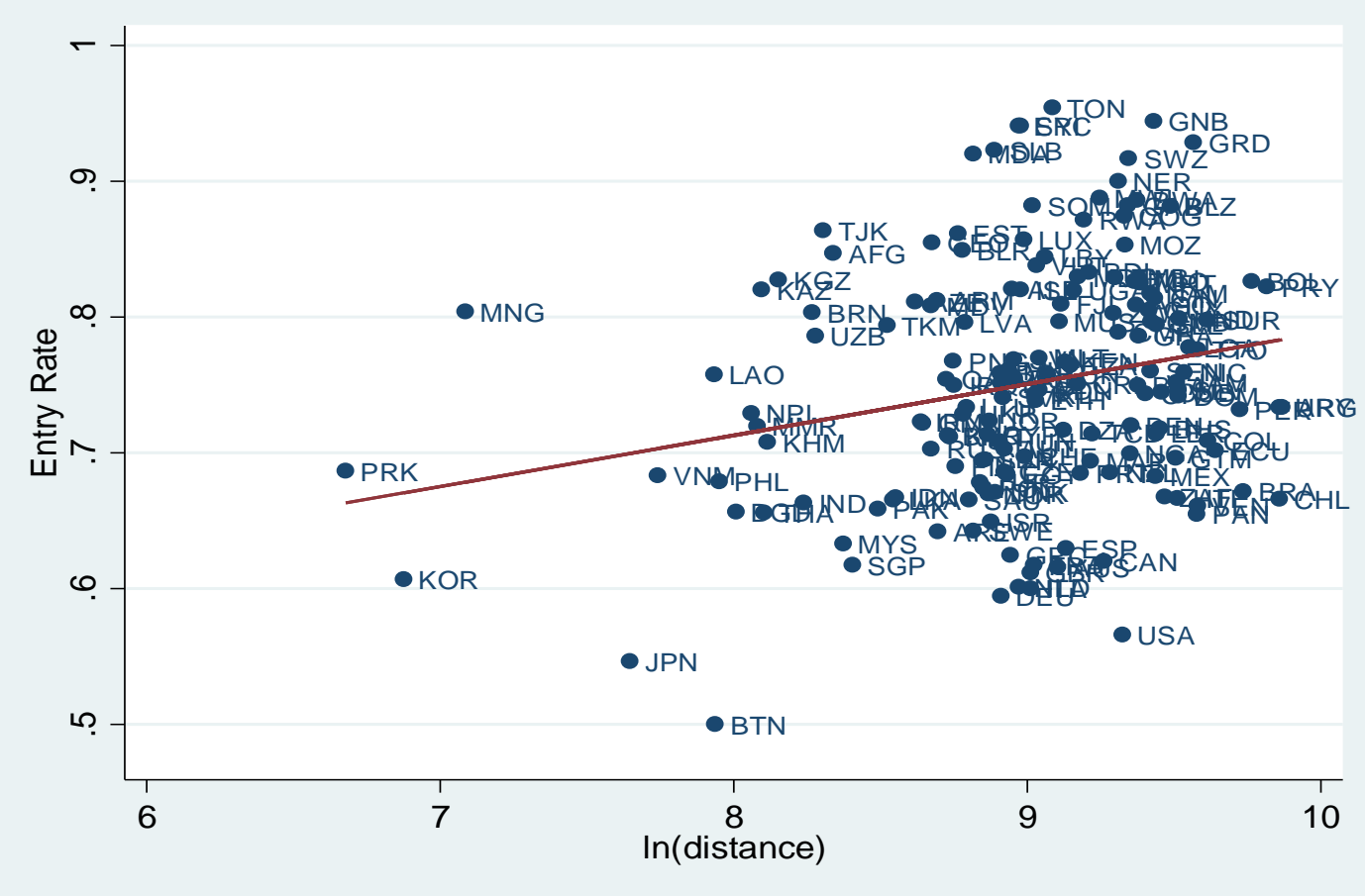

Note: Entry rate $=$ Number of new exporters in $t /$ Total number of exporters in $t$. In(distance) is the log of distance between China and each destination country.

Fig 4: Firms' Exit Rate and Distance by Country (2003)

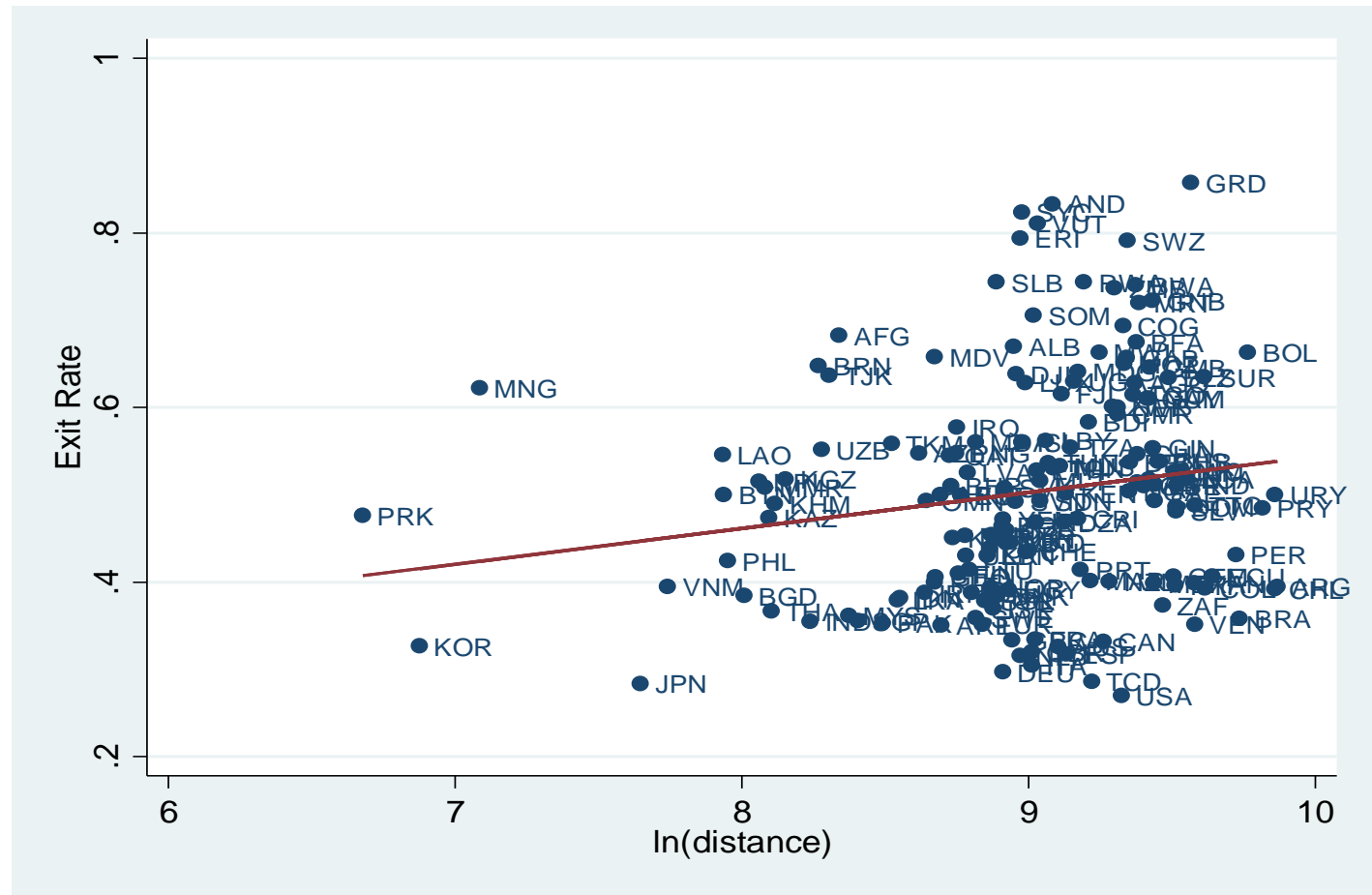

Note: Exit rate $=$ Number of new exporters that exit in $t+1 /$ Number of new exporters in $t$.

Reentrants after exits are not considered as true exits. In(distance) $s$ the log of distance between China and each destination country. 
Fig 5: Firms' Entry Rate and log Nb of Existing Exporters by Country (2003)

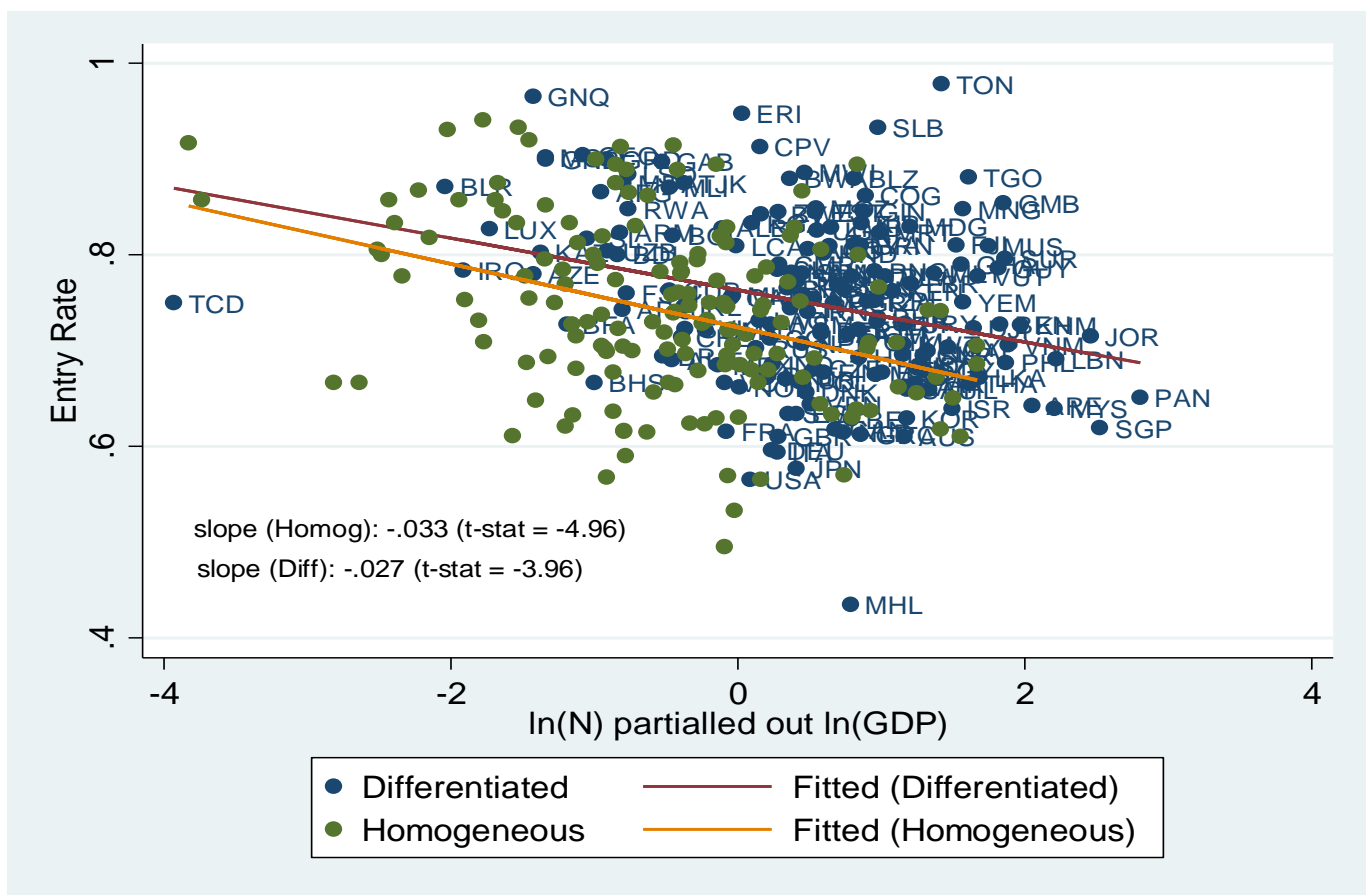

Note: Entry rate $=$ Number of new exporters in $t /$ Total number of exporters in $t . . \ln (\mathrm{N})$ partialled out $\ln (G D P)$ is the log of number of existing exporters to each country in the previous year, after the correlation with each destination's GDP partialled out in a first-stage regression.

Fig 6: Firms' Exit Rate and log Nb of Existing Exporters by Country (2003)

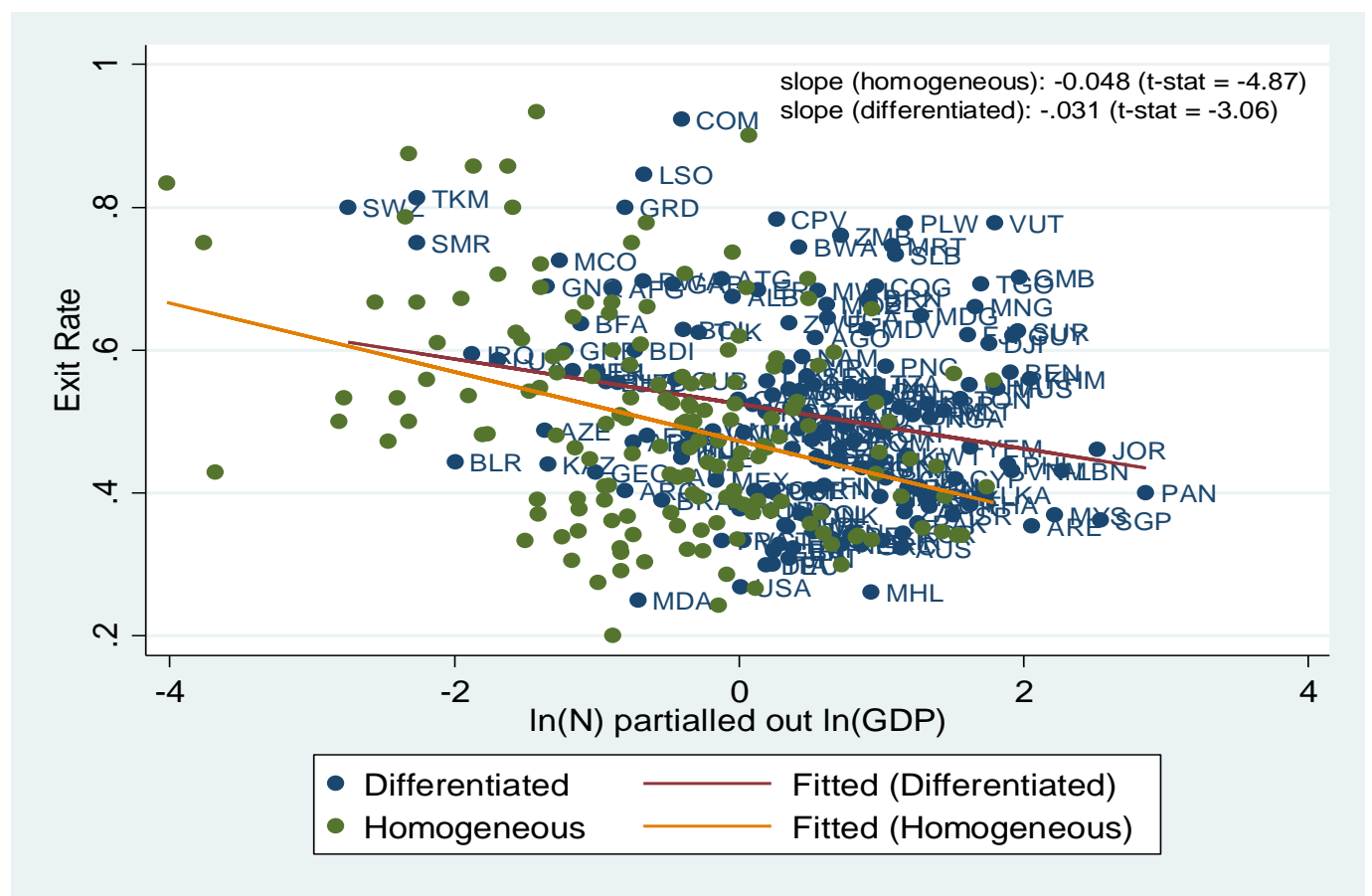

Note: Exit rate $=$ Number of new exporters that exit in $t+1 /$ Number of new exporters in $t$. Reentrants after exits are not considered as true exits. In(N) partialled out $\ln (G D P)$ is the log of number of existing exporters to each country in the previous year, after the correlation with each 
Fig 7: Firms' Entry and log GDP by Country (2003)

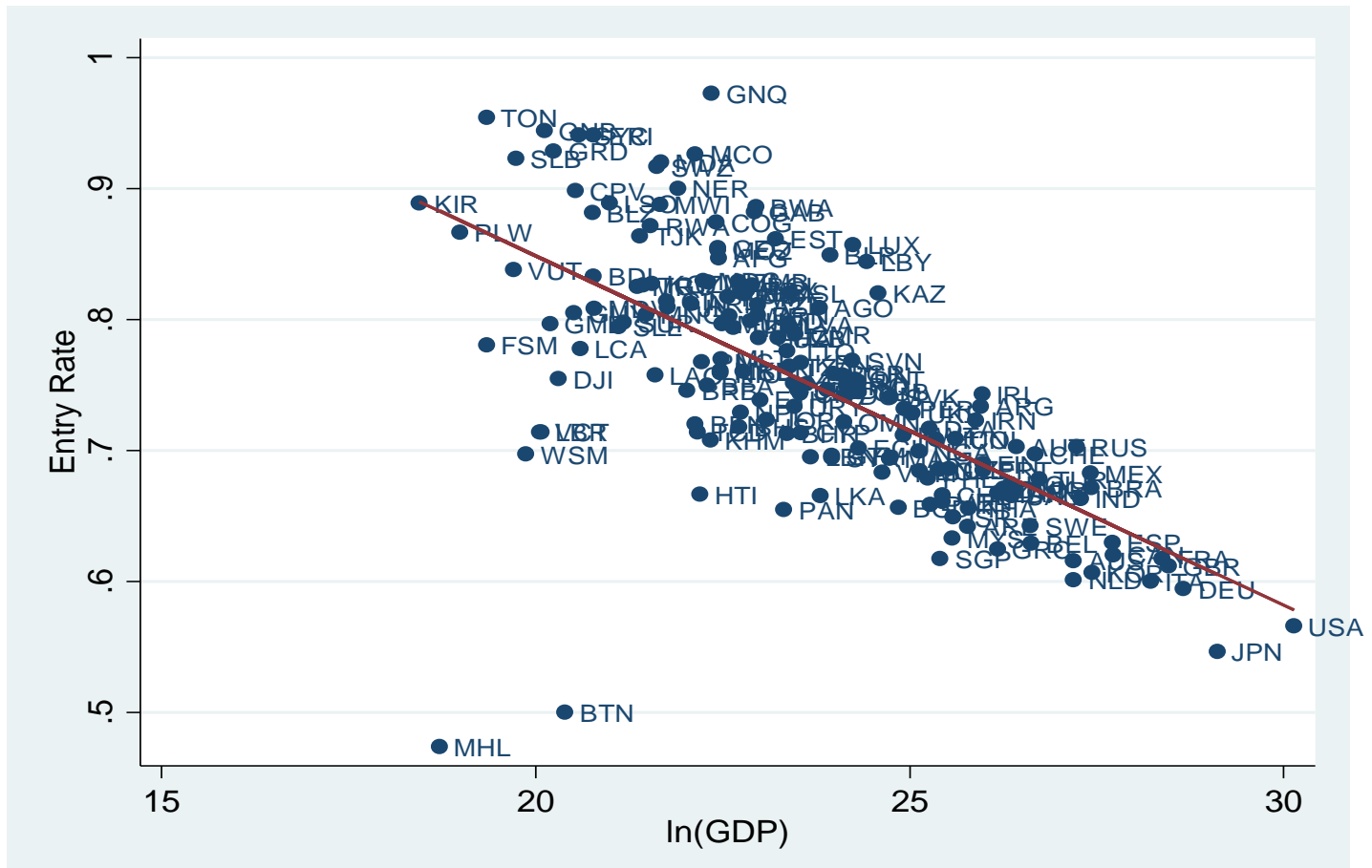

Note: Entry rate $=$ Number of new exporters in $\mathrm{t} /$ Total number of exporters in $\mathrm{t}$.

Fig 8: Firms' Entry and log GDP by Country (2003)

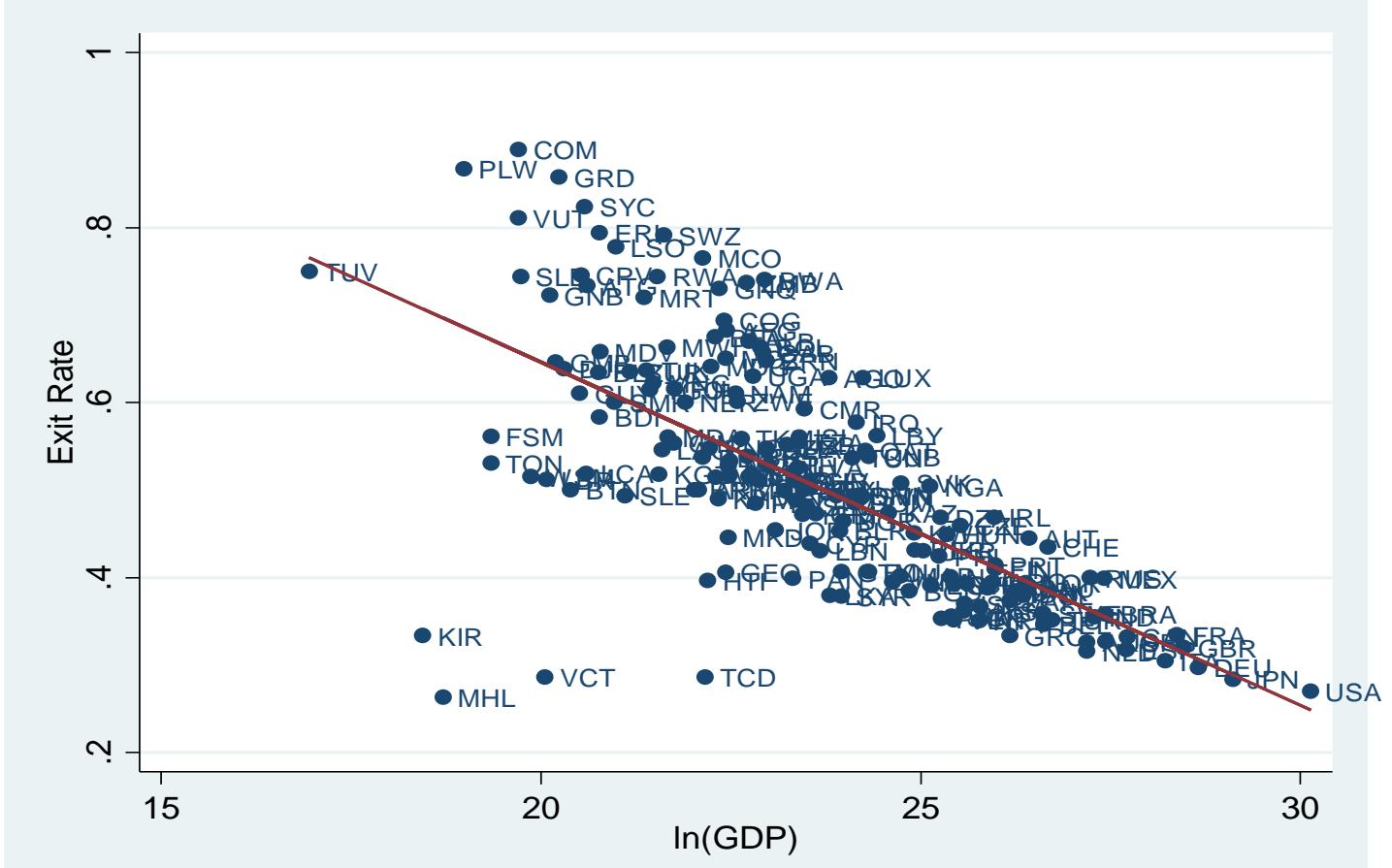

Note: Exit rate $=$ Number of new exporters that exit in $t+1 /$ Number of new exporters in $t$. Reentrants after exits are not considered as true exits. 
Figure 9: Jensen's Inequality and the Expected Profit under an Option of Exiting

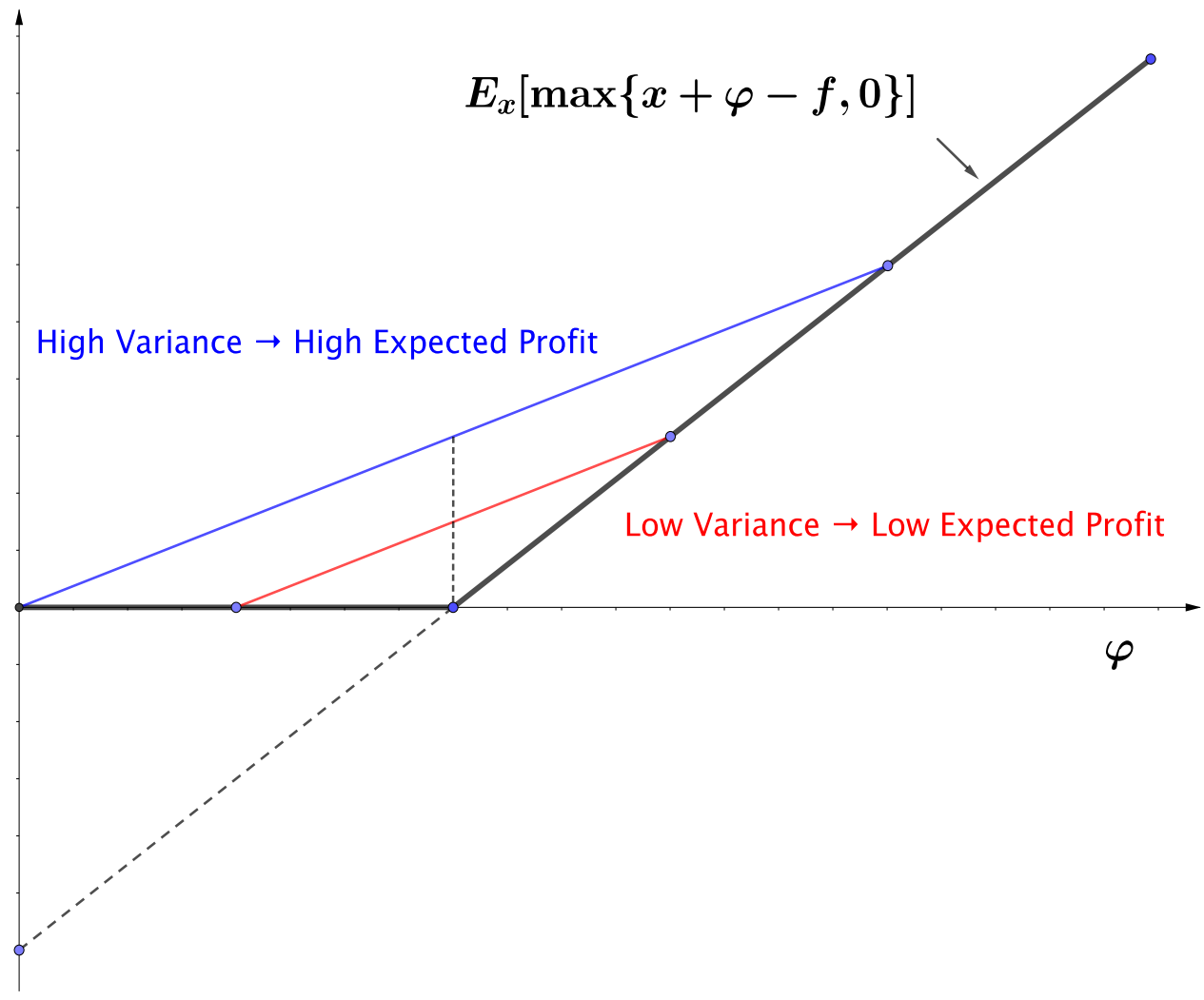


Figure 10: Entry, Exit, and Determination of Exit Rate

$$
\text { Exit Rate }=\frac{G\left(\varphi_{2}^{*}\right)-G\left(\varphi_{1}^{*}\right)}{1-G\left(\varphi_{1}^{*}\right)}
$$

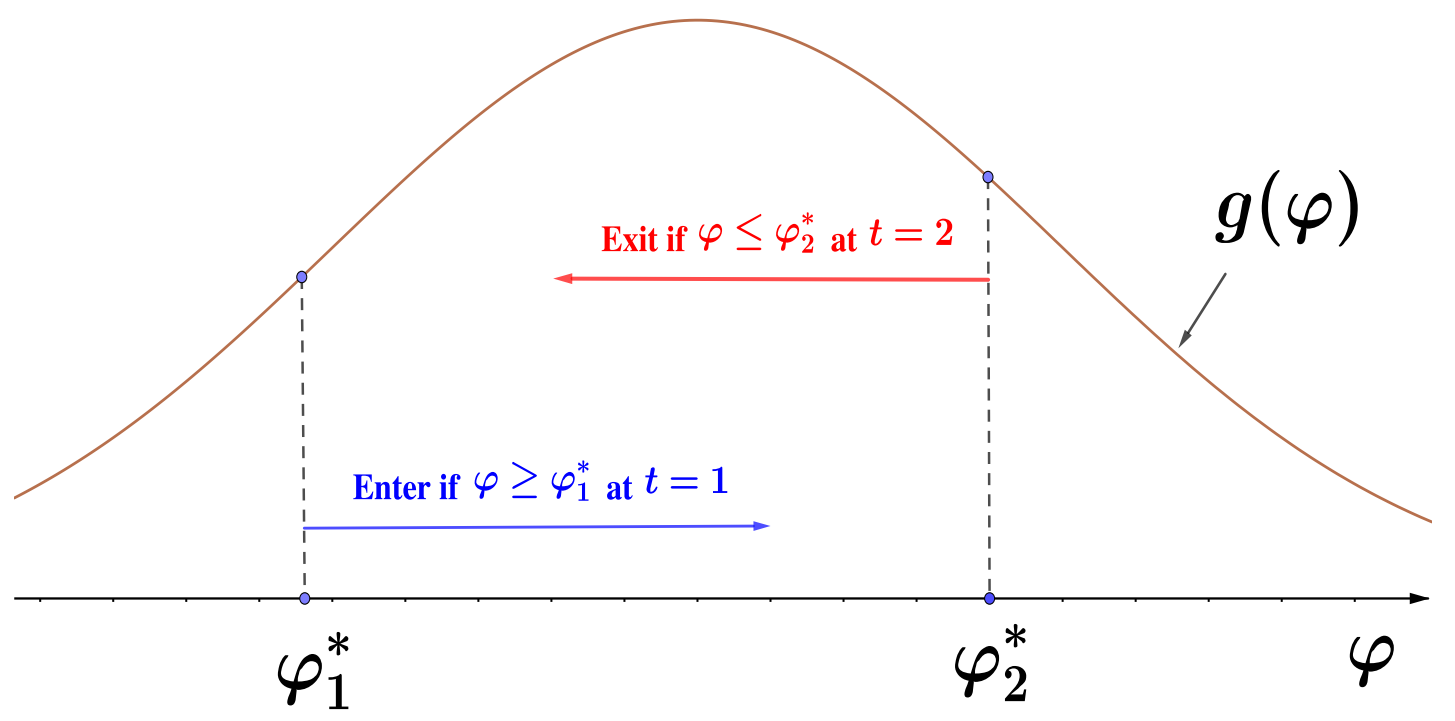


Table 1: Summary Statistics of China's Customs Data

\begin{tabular}{lccc}
\hline \hline Panel A: Firm level & & & \\
\hline Number of destinations & 2001 & 2003 & 2005 \\
\hline Mean & 5 & 6 & 6 \\
Median & 2 & 2 & 3 \\
Stand. Dev & 7 & 8 & 9 \\
& & & \\
Exports (thousands US\$) & & & \\
Mean & 1011 & 1258 & 1462 \\
Median & 196 & 251 & 298 \\
Stand. Dev & 8893 & 9926 & 13816 \\
& & & \\
Panel B: Aggregate Level & \multicolumn{3}{c}{} \\
\hline Number of firms & 27740 & 45471 & 82836 \\
Number of destinations & 173 & 182 & 195 \\
Exports (US\$ millions) & 28044 & 57202 & 121102 \\
\hline \hline
\end{tabular}

China's Customs transaction-level trade data (2001-2005). Only nonprocessing (ordinary) exporters are included. Trading companies (wholesale-retail firms) are all excluded. 
Table 2: Average Firms' Entry and Exit Rates by Year

\begin{tabular}{|c|c|c|c|c|c|c|c|}
\hline Year & 2001 & 2002 & 2003 & 2004 & 2005 & 2006 & $\begin{array}{c}\text { Average } \\
\text { across years }\end{array}$ \\
\hline \multicolumn{8}{|l|}{ Panel A } \\
\hline Mean Entry Rate & $80.86 \%$ & $79.27 \%$ & $76.59 \%$ & $77.81 \%$ & $80.59 \%$ & $71.65 \%$ & $77.79 \%$ \\
\hline Mean Exit Rate & $60.90 \%$ & $58.49 \%$ & $57.56 \%$ & $61.00 \%$ & $67.70 \%$ & $55.36 \%$ & $60.17 \%$ \\
\hline Median Entry Rate & $80.89 \%$ & $77.91 \%$ & $75.18 \%$ & $77.40 \%$ & $79.55 \%$ & $71.29 \%$ & $77.04 \%$ \\
\hline Median Exit Rate & $59.20 \%$ & $55.56 \%$ & $56.25 \%$ & $59.09 \%$ & $65.77 \%$ & $53.19 \%$ & $58.18 \%$ \\
\hline Number of Countries & 181 & 183 & 185 & 183 & 189 & 186 & 185 \\
\hline \multicolumn{8}{|l|}{ Panel B: Africa } \\
\hline Mean Entry Rate & $84.43 \%$ & $82.45 \%$ & $82.24 \%$ & $83.73 \%$ & $85.51 \%$ & $77.25 \%$ & $82.60 \%$ \\
\hline Mean Exit Rate & $64.99 \%$ & $63.16 \%$ & $66.61 \%$ & $71.24 \%$ & $75.42 \%$ & $63.67 \%$ & $67.52 \%$ \\
\hline Median Entry Rate & $84.62 \%$ & $81.62 \%$ & $81.74 \%$ & $82.55 \%$ & $84.56 \%$ & $75.37 \%$ & $81.74 \%$ \\
\hline Median Exit Rate & $62.07 \%$ & $60.69 \%$ & $65.87 \%$ & $69.82 \%$ & $74.39 \%$ & $61.54 \%$ & $65.73 \%$ \\
\hline Number of Countries & 53 & 53 & 53 & 53 & 53 & 53 & 53 \\
\hline
\end{tabular}

China's Customs data and authors' calculation. The mean and median entry rates are both equal to 1 in 2000 as it is the first year in our sample. Those observations will be dropped in our regressions below. 
Table 3: Firms that Entered in 2001, Exited in 2002 and Re-entered in the Future

\begin{tabular}{|c|c|c|c|c|c|c|c|}
\hline & $\begin{array}{c}\text { Number Entrants } \\
\text { in } 2001 \\
\end{array}$ & $\begin{array}{c}\text { Exit from the } \\
\text { market in } 2002\end{array}$ & $\begin{array}{l}\text { Exit in } 2002 \text { but } \\
\text { re-enter in } 2003\end{array}$ & $\begin{array}{c}\text { Exit in } 2002-2003 \\
\text { but re-enter in } \\
2004 \\
\end{array}$ & $\begin{array}{c}\text { Exit in 2002-2004 } \\
\text { but re-enter in } \\
2005 \\
\end{array}$ & $\begin{array}{c}\text { Exit in 2002-2005 } \\
\text { but re-enter in } \\
2006 \\
\end{array}$ & $\begin{array}{c}2002 \text { that re- } \\
\text { enter in } 2003- \\
2006\end{array}$ \\
\hline Across Markets & 133,972 & $64.04 \%$ & $4.99 \%$ & $2.38 \%$ & $1.33 \%$ & $0.89 \%$ & $14.97 \%$ \\
\hline Differentiated Sectors & 97838 & $64.86 \%$ & $4.94 \%$ & $2.36 \%$ & $1.32 \%$ & $0.87 \%$ & $14.62 \%$ \\
\hline Homogeneous Sectors & 36134 & $61.83 \%$ & $5.12 \%$ & $2.44 \%$ & $1.36 \%$ & $0.94 \%$ & $15.96 \%$ \\
\hline Distant Destinations & 56035 & $64.68 \%$ & $4.94 \%$ & $2.52 \%$ & $1.32 \%$ & $0.99 \%$ & $15.12 \%$ \\
\hline Nearby Destinations & 77937 & $63.59 \%$ & $5.02 \%$ & $2.28 \%$ & $1.33 \%$ & $0.82 \%$ & $14.86 \%$ \\
\hline
\end{tabular}

The sample contains firms that first started exporting to a market (a country-HS2 pair) in 2001, but not in 2000. A sector (HS2) is considered differentiated based on

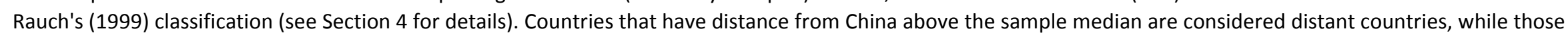
with distance below the median are considered nearby destinations. 
Table 4: Information Asymmetry, Learning, and Exit Rates

\begin{tabular}{|c|c|c|c|c|c|c|}
\hline \multirow{3}{*}{$\begin{array}{l}\text { Dep Var } \\
\text { Measure of product differentiation }\end{array}$} & $(1)$ & $(2)$ & (3) & (4) & $(5)$ & $(6)$ \\
\hline & \multicolumn{6}{|c|}{ Rate of exit among firms exporting to a market from a Chinese city } \\
\hline & - & - & & & Estir & $e d \sigma_{z}$ \\
\hline \multirow[t]{2}{*}{$\ln ($ dist $)$} & $0.0311^{* * *}$ & & $0.0422 * * *$ & & $0.0377^{* * *}$ & \\
\hline & $(17.179)$ & & $(15.302)$ & & $(20.520)$ & \\
\hline \multirow[t]{2}{*}{ In(nb neighbors in the same city) } & & $-0.150 * * *$ & & $-0.125 * * *$ & & $-0.145 * * *$ \\
\hline & & $(-15.808)$ & & $(-14.572)$ & & $(-8.553)$ \\
\hline \multirow[t]{2}{*}{ Diff $x \ln$ (dist) } & & & $-0.0173 * * *$ & & $-0.00787 * *$ & \\
\hline & & & $(-5.326)$ & & $(-20.824)$ & \\
\hline \multirow[t]{2}{*}{ Diff $x \ln$ (nb neighbors) } & & & & 0.00525 & & $0.0187^{* *}$ \\
\hline & & & & $(1.008)$ & & $(2.222)$ \\
\hline HS2-Year Fixed Effects & $\sqrt{ }$ & $\sqrt{V}$ & $\sqrt{ }$ & $\sqrt{ }$ & $\sqrt{ }$ & $\sqrt{ }$ \\
\hline City-Year Fixed Effects & V & $\sqrt{ }$ & V & $\sqrt{ }$ & $v$ & $\sqrt{ }$ \\
\hline Nb. Of Obs. & 293863 & 302005 & 293863 & 295890 & 282563 & 289191 \\
\hline R-squared & .1 & .173 & .1 & .249 & .1 & .24 \\
\hline
\end{tabular}

The sample includes all city-country-sector pairs in which Chinese firms ever started exporting in a new market during the 2002-2004 period, but did not export in the previous two years (i.e., $\mathrm{t}-1$ and $\mathrm{t}-2$ ). The sample is constructed in a way eliminate temporal exiters that immediately re-entered in $\mathrm{t}+1$, in light of the findings in Table 3. A market is defined as a country-sector pair, while a firm's neighborhood is defined as the city in which it operates. Standard errors are clustered by city and are robust to clustering at other levels. T-statistics are reported in parentheses. 
Table 5: Learning from Neighbors and Firm's Entry

\begin{tabular}{|c|c|c|c|c|c|c|}
\hline \multirow[b]{2}{*}{ Dep Var } & (1) & $(2)$ & (3) & (4) & (5) & (6) \\
\hline & \multicolumn{6}{|c|}{ A firm's entry dummy (country-sector) } \\
\hline Signal (city-country-hs2) & $\begin{array}{c}0.102 * * * \\
(44.129)\end{array}$ & $\begin{array}{c}0.0981 * * * \\
(41.681)\end{array}$ & $\begin{array}{c}0.115^{* * *} \\
(37.193)\end{array}$ & $\begin{array}{c}0.108 * * * \\
(16.056)\end{array}$ & $\begin{array}{c}0.106 * * * \\
(15.425)\end{array}$ & $\begin{array}{c}0.0705^{* * *} \\
(7.819)\end{array}$ \\
\hline Nb. of neighbors $x$ Signal & $\begin{array}{c}0.0289 * * * \\
(22.662)\end{array}$ & $\begin{array}{c}0.0279 * * * \\
(21.821)\end{array}$ & $\begin{array}{c}0.0408 * * * \\
(25.120)\end{array}$ & $\begin{array}{c}0.0575^{* * *} \\
(16.088)\end{array}$ & $\begin{array}{c}0.0558 * * * \\
(15.359)\end{array}$ & $\begin{array}{c}0.0800 * * * \\
(16.898)\end{array}$ \\
\hline Nb. of neighbors (city-country-hs2) & $\begin{array}{c}-0.321 * * * \\
(-25.586)\end{array}$ & $\begin{array}{c}-0.309 * * * \\
(-24.496)\end{array}$ & $\begin{array}{c}-0.438 * * * \\
(-28.427)\end{array}$ & $\begin{array}{c}-0.596 * * * \\
(-20.147)\end{array}$ & $\begin{array}{c}-0.579 * * * \\
(-19.229)\end{array}$ & $\begin{array}{c}-0.772 * * * \\
(-20.024)\end{array}$ \\
\hline Estimated TFP (firm-sector level) & & & $\begin{array}{c}0.00907 * * * \\
(11.888)\end{array}$ & & & $\begin{array}{c}0.00895^{* * *} \\
(11.390)\end{array}$ \\
\hline$\sigma_{z} \times$ Signal & & & & $\begin{array}{c}-0.0106 * * \\
(-2.251)\end{array}$ & $\begin{array}{c}-0.0123 * * \\
(-2.505)\end{array}$ & $\begin{array}{c}0.0278 * * * \\
(4.399)\end{array}$ \\
\hline$\sigma_{z} \times \mathrm{Nb}$. of neighbors $\times$ Signal & & & & $\begin{array}{c}-0.0227 * * * \\
(-10.150)\end{array}$ & $\begin{array}{c}-0.0222^{* * *} \\
(-9.709)\end{array}$ & $\begin{array}{c}-0.0298 * * * \\
(-9.959)\end{array}$ \\
\hline$\sigma_{z} \times \mathrm{Nb}$. of neighbors & & & & $\begin{array}{c}0.222 * * * \\
(11.162)\end{array}$ & $\begin{array}{c}0.218^{* * *} \\
(10.780)\end{array}$ & $\begin{array}{c}0.257^{* * *} \\
(10.113)\end{array}$ \\
\hline City $x$ hs 2 x year fixed effects & $\mathrm{V}$ & $\sqrt{ }$ & $\mathrm{V}$ & $\mathrm{V}$ & $\mathrm{V}$ & $\mathrm{V}$ \\
\hline Country $x$ hs $2 \times$ year fixed effects & V & v & v & V & v & V \\
\hline City $x$ country fixed effects & $\mathrm{V}$ & V & V & V & $\mathrm{V}$ & $\mathrm{V}$ \\
\hline Firm-year fixed effects & & $\sqrt{ }$ & $\sqrt{ }$ & & $\mathrm{V}$ & $\mathrm{V}$ \\
\hline Nb. Of Obs. & 735876 & 732444 & 121836 & 711361 & 707869 & 118887 \\
\hline R-squared & .687 & .703 & .867 & .69 & .705 & .871 \\
\hline
\end{tabular}

The sample considers markets in the 46 Sub-Saharan African countries. The restricted sample includes all new country-sector pairs in which Chinese firms could potentially enter during the 2002-2006 period, but did not sell in the previous two years (i.e., t-1 and t-2). Existing exporters are dropped from the sample, so that a firm's entry propensity is compared with "no entry". Standard errors are clusterd at the city-destination level, and are robust to clustering at other levels. T-statistics are reported in parentheses. 


\begin{tabular}{|c|c|c|c|c|}
\hline \multirow[b]{2}{*}{ Dep Var } & (1) & $(2)$ & (3) & (4) \\
\hline & \multicolumn{4}{|c|}{ A firm's entry dummy (country-sector) } \\
\hline Nb. entrants t & $\begin{array}{c}0.0986 * * * \\
(12.886)\end{array}$ & $\begin{array}{c}0.154^{* * *} \\
(13.887)\end{array}$ & $\begin{array}{c}0.140 * * * \\
(4.013)\end{array}$ & $\begin{array}{c}0.235^{* * *} \\
(5.816)\end{array}$ \\
\hline Nb. entrants $t+2$ & $\begin{array}{c}-0.0114 * * * \\
(-4.814)\end{array}$ & $\begin{array}{c}-0.0256 * * * \\
(-6.286)\end{array}$ & $\begin{array}{c}-0.0158^{* *} \\
(-2.433)\end{array}$ & $\begin{array}{c}-0.0294 * * * \\
(-2.759)\end{array}$ \\
\hline$\sigma_{\mathrm{z}} \times \mathrm{Nb}$. entrants $\mathrm{t}$ & & & $\begin{array}{l}-0.0376 \\
(-1.402)\end{array}$ & $\begin{array}{c}-0.0722 * * \\
(-2.158)\end{array}$ \\
\hline$\sigma_{\mathrm{z}} \times \mathrm{Nb}$. entrants $\mathrm{t}+2$ & & & $\begin{array}{c}0.00342 \\
(0.831)\end{array}$ & $\begin{array}{c}0.00308 \\
(0.373)\end{array}$ \\
\hline Estimated TFP (firm-sector level) & & $\begin{array}{c}0.0167^{* * *} \\
(19.425)\end{array}$ & & $\begin{array}{c}0.0175^{* * *} \\
(18.161)\end{array}$ \\
\hline Firm $x$ year fixed effects & $\bar{V}$ & $\bar{v}$ & $\bar{v}$ & $\mathrm{~V}$ \\
\hline City $x$ hs $2 \times$ year fixed effects & $\sqrt{ }$ & $\sqrt{ }$ & $\mathrm{v}$ & v \\
\hline Country $\mathrm{x}$ hs $2 \mathrm{x}$ year fixed effects & v & v & 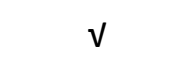 & v \\
\hline City $x$ country fixed effects & $\sqrt{ }$ & $\checkmark$ & $\sqrt{ }$ & $v$ \\
\hline Nb. Of Obs. & 2022857 & 132253 & 1715670 & 119300 \\
\hline R-squared & .0956 & .386 & .1 & .39 \\
\hline
\end{tabular}

The sample considers markets in the 46 Sub-Saharan African countries. The restricted sample includes all new country-sector pairs in which Chinese firms could potentially enter during the 2002-2006 period, but did not sell in the previous two years (i.e., $\mathrm{t}-1$ and $\mathrm{t}-2$ ). Existing exporters are dropped from the sample, so that a firm's entry propensity is compared with "no entry". Standard errors are clusterd at the citydestination level, and are robust to clustering at other levels. T-statistics are reported in parentheses. 
Table A1: Information Asymmetry, Learning, and Exit Rates (Provinces as Neighborhoods)

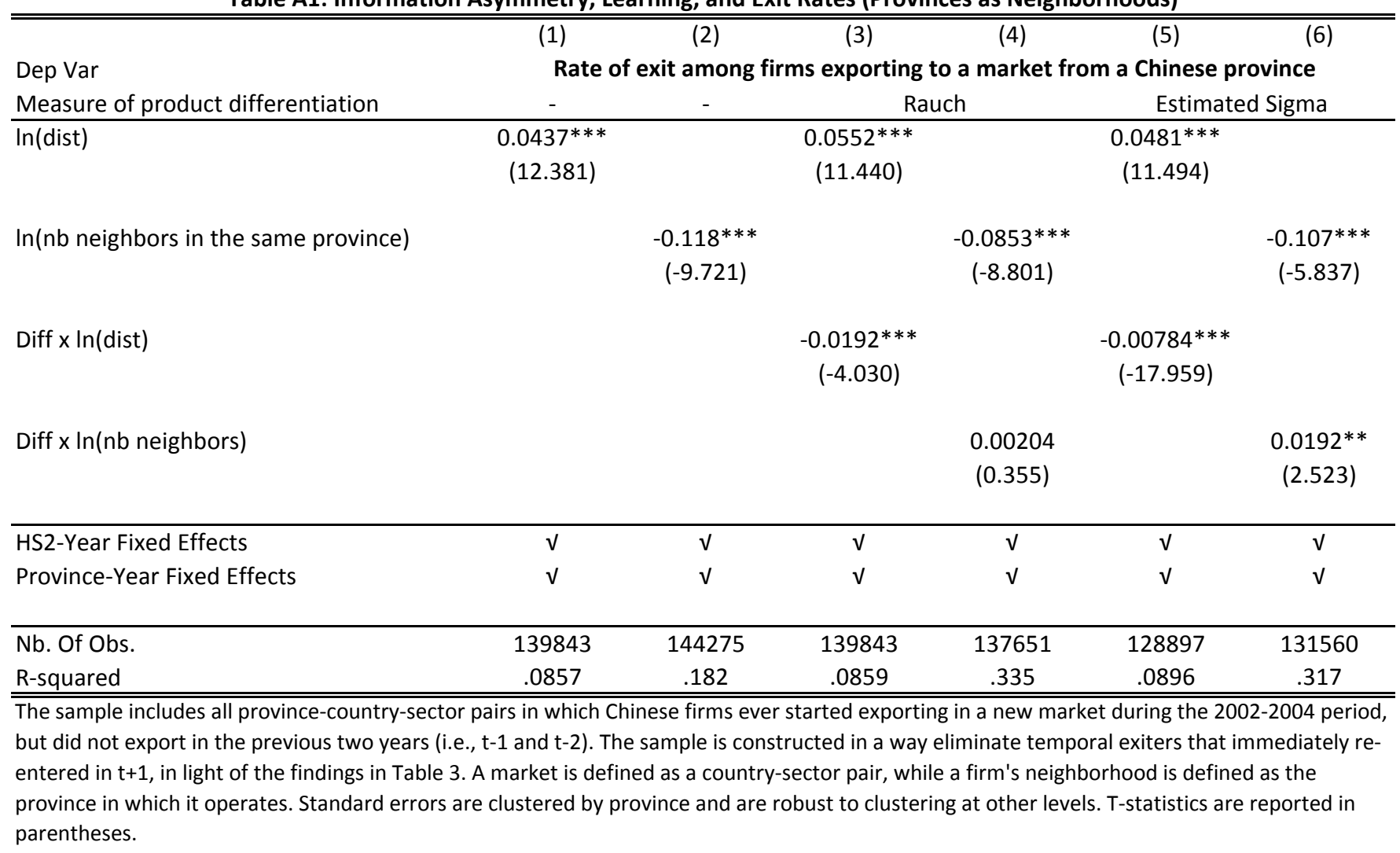

